Revista lus et Praxis, Año 23, No 1, 2017, pp. 153 - 194

ISSN 0717 - 2877

Universidad de Talca - Facultad de Ciencias Jurídicas y Sociales

El derecho del deudor a la subsanación o corrección del cumplimiento no conforme (right to cure).

Acercamiento desde los instrumentos de derecho contractual uniforme hacia el derecho chileno de contratos Juan Ignacio Contardo González

Trabajo recibido el 29 de octubre de 2015 y aprobado el 4 de mayo de 2016

\title{
El derecho del deudor a la subsanación o corrección del cumplimiento no conforme (right to cure). Acercamiento desde los instrumentos de derecho contractual uniforme hacia el derecho chileno de contratos
}

THE DEBTOR'S RIGHT TO THE RECTIFICATION OR CORRECTION OF THE NON-CONFORMING PERFORMANCE (RIGHT TO CURE). APPROACH FROM UNIFORM CONTRACT LAW INSTRUMENTS TO CHILEAN CONTRACT LAW

Juan Ignacio Contardo GonZÁlez*

REsUMEN

El estudio explora la institución de la subsanación o corrección del cumplimiento conforme (righy to cure) en los instrumentos de derecho contractual uniforme y su posible adopción en el derecho chileno de contratos.

ABSTRACT

This paper explores the right to cure institution in the uniform contract instruments, and its possible adoption in chilean contract law.

PaLABRAS CLAVE

Cumplimiento conforme al contrato, subsanación del incumplimiento.

KEYWORDS

Conforming performance to the contract, cure by debtor.

\footnotetext{
* Profesor de Derecho Civil, Diego Portales (Chile). Doctor en Derecho, Universidad de los Andes (Chile). Licenciado en Ciencias Jurídicas, Universidad Adolfo Ibáñez. Correo electrónico: juan.contardo@mail.udp.cl. El presente trabajo forma parte del proyecto Fondecyt de iniciación № 11130509 : "Hacia un sistema de medidas anticipatorias frente al incumplimiento contractual", del cual el autor es investigador responsable.

El autor agradece a los profesores Antonio Manuel Morales Moreno y Lis Paula San Miguel Pradera de la Universidad Autónoma de Madrid, y Djakhongir Saidov del King's College of London por su acogimiento y ayuda bibliográfica en las estadías de investigación realizadas en España e Inglaterra durante los meses de enero de 2014 y 2015, respectivamente, en la que se generó parte de esta investigación. Cabe hacer presente que la estadía de investigación durante el mes de enero de 2015 se realizó en la University of Birmingham, casa de estudios que albergaba, en ese tiempo, al profesor Saidov.
} 


\section{Introducción}

Una de las tendencias predominantes en la modernización del derecho de las obligaciones es favorecer el cumplimiento conforme de los contratos. La noción de cumplimiento conforme importa la satisfacción del interés del acreedor para determinar que el cumplimiento es suficiente para, por una parte, establecer que la obligación ha sido satisfecha; y por la otra, la liberación del deudor de su obligación.

Esto supone, desde una perspectiva, un cambio en la forma en cómo se concibe el problema del incumplimiento. Hoy en día éste no es considerado sólo como el exacto cumplimiento de la obligación pactada, sino como una manera de satisfacción del interés del acreedor, aun cuando el deudor no haya dado cumplimiento estricto a lo establecido en el contrato ${ }^{1}$.

De esta manera, en el moderno derecho de la contratación aparecen medidas alternativas que permiten determinar que el interés del acreedor ha sido satisfecho y, por tanto, la obligación ha sido cumplida, aun cuando se presente una desviación del programa contractual, que el deudor puede corregir.

Sin embargo, esta noción más amplia del incumplimiento, desde otro punto de vista, no releva al deudor y acreedor de ciertas obligaciones y cargas que favorecen la conformidad, lo que permite la estabilidad del contrato en contra de su terminación por cualquier incumplimiento, aun mínimo, de menor cuantía o irrelevante.

Podemos sostener que hay al menos dos instituciones que ayudan a configurar de alguna forma la noción de cumplimiento conforme, más allá de aquellas que establecen positivamente la falta de conformidad. Éstas son, a nuestro entender, el derecho del deudor a la subsanación del cumplimiento (cure by debtor) y el plazo adicional para el cumplimiento (aditional time for performance). En virtud de la primera institución se permite al deudor corregir una prestación defectuosa frente a una falta de conformidad; en cambio, la segunda permite al deudor cumplir la prestación después del plazo fijado para el cumplimiento de la obligación. Esta investigación sólo se enfocará en la subsanación del cumplimiento.

Ambas instituciones no son reconocidas de manera expresa por el Código Civil chileno, que es la regla general en el derecho chileno de contratos. Tampoco en la Ley sobre Protección a los Derechos de los Consumidores, Ley No 19.496 de 1997.

1 Sobre el particular, véase Morales (2006), pp. 196 y ss.; y en Chile, VIDAL (2007), pp. 44 y ss. 
Sin embargo, sí lo son por los instrumentos de derecho contractual uniforme. En especial, la Convención de Viena sobre Compraventa Internacional de Mercaderías (en adelante, $\mathrm{CISG}^{2}$ ), los Principios Unidroit sobre Contratos Comerciales Internacionales (en adelante, $\mathrm{PICC}^{3}$ ), los Principios Europeos de Derecho de los Contratos (en adelante, $\mathrm{PECL}^{4}$ ), el Borrador para un Marco Común de Referencia (en adelante, DFCR ${ }^{5}$ y la "Propuesta de Reglamento del Parlamento Europeo y del Consejo relativo a una normativa común de compraventa europea" (en adelante, CESL) ${ }^{6}$. En todos estos textos existe regulación

2 Promulgada a través del Decreto № 544 del Ministerio de Relaciones Exteriores de 31 de mayo de 1990 y publicada en el Diario Oficial el 3 de octubre de 1990.

${ }^{3}$ Los PICC fueron elaborados por el Institut International pour l'unification du Droit Prive (Unidroit), en una primera versión de 1994, y con dos revisiones posteriores, de 2004 y 2010. Se han tenido a la vista todas las versiones, sin embargo, se ha trabajado con la última para los efectos de esta investigación. Asimismo, se ha trabajado tanto con el texto en inglés (disponible en: http://www.unidroit. org/english/principles/contracts/principles2010/integralversionprinciples2010-e.pdf. Última visita: 22 de enero de 2015), como con la traducción al español otorgada por el mismo Unidroit (disponible en: http://www.unidroit.org/spanish/principles/contracts/principles2010/blackletter2010-spanish.pdf [visitado 22/01/2015]).

${ }^{4}$ Los PECL son fruto del esfuerzo académico de la primera y segunda Commission on European Contract Law (denominada generalmente "Comisión Lando", en atención a su presidente), cuyo objeto fue la fundación de un derecho uniforme para la Unión Europea, una reformulación de la Lex Mercatoria, un modelo para un desarrollo judicial y legislativo en materia de derecho de contratos y base para la armonización del derecho contractual europeo: LANDO y BEALE (2000), pp. xxi y ss.

${ }^{5}$ El DCFR ("Borrador para un marco común de referencia") es un documento de carácter académico elaborado por el Study Group on a European Civil Code y el Research Group on Existing EC Private Law (también denominado "Acquis Group"), que tiene por objeto establecer principios, definiciones y reglas modelo que sirve de base para una redacción futura de un "marco común de referencia" para la Unión Europea; y que éste, a su vez, sirva de base en el futuro para la armonización de la legislación del derecho privado contractual europeo: VON BAR y otros (2009), p. 36.

${ }^{6}$ La CESL ("Propuesta de Reglamento del Parlamento Europeo y del Consejo relativo a una normativa común de compraventa europea"), de fecha 11 de octubre de 2011 (COM[2011] 635 final), según su exposición de motivos, tiene como objetivo general "mejorar el establecimiento y el funcionamiento del mercado interior facilitando la expansión del comercio transfronterizo a las empresas y las compras transfronterizas a los consumidores". Este objetivo, dice la exposición de motivos a continuación, "puede alcanzarse mediante la puesta a disposición de un corpus uniforme y autónomo de normas de Derecho contractual que incluya disposiciones para proteger a los consumidores, la normativa común de compraventa europea, que ha de considerarse un segundo régimen de Derecho contractual dentro de los ordenamientos jurídicos de los distintos Estados miembros": CE (2011), p. 4.

El esfuerzo, sin embargo, no rendirá sus frutos en el tiempo inmediato, puesto que la Propuesta fue retirada a través del Anexo 2 a la Comunicación de la Comisión al Parlamento Europeo, al Consejo, al Comité Europeo Económico y Social y al Comité de las Regiones, de fecha 16 de diciembre de 2014 (http://ec.europa.eu/atwork/pdf/cwp_2015_withdrawals_en.pdf [visitado 23/01/2015]). El fundamento del retiro fue la necesidad de modificar la propuesta para repotenciar el comercio digital individual en un nuevo documento. 
positiva de ambas instituciones, y lo que nos importa en esta investigación, de la subsanación del cumplimiento ${ }^{7}$.

En términos simples, la subsanación importa otorgar una segunda oportunidad para el cumplimiento conforme, aun cuando el deudor no haya cumplido en forma, e incluso, permitiéndole cumplir más allá del plazo original destinado para el cumplimiento. Como un autor lo sugiere, esta institución puede resumirse en una máxima: "si a la primera oportunidad no tienes éxito, intenta realizarlo de nuevo" ${ }^{\prime \prime}$.

A pesar de su falta de regulación por el Código Civil, creemos que una lectura desde los instrumentos de derecho contractual uniforme puede complementar los avances de la doctrina en la configuración de un régimen de falta de conformidad que permite abordar de forma más realista el problema del incumplimiento y sus consecuencias.

Tal como se expondrá en esta investigación, el derecho a la subsanación del incumplimiento por el deudor permite delimitar la noción de cumplimiento conforme, restringiendo de alguna manera el derecho del acreedor a toda la elección de los remedios contractuales, en especial, de la resolución. Además, racionaliza el ejercicio de los derechos del acreedor. Así, permite al deudor mantener el contrato, aun a pesar del interés primario del acreedor en darlo por terminado de manera drástica; y también, le da una nueva oportunidad al deudor para satisfacer el interés del acreedor, lo que al final de cuentas debe evaluar el tribunal. Este es el sentido que le ha dado la jurisprudencia internacional accesible que ha fallado de acuerdo con la CISG, y que de alguna manera permite sostener que el right to cure se configura como una limitación al derecho del acreedor para demandar la resolución del contrato. Esta idea que tratamos de exponer en este trabajo complementa los avances de la doctrina nacional sobre la noción de incumplimiento esencial ${ }^{9}$, y de incumplimiento resolutorio ${ }^{10}$.

Además, este trabajo intenta realizar un aporte en relación con la noción que hemos propuesto en otra oportunidad de medidas anticipatorias $y$, en concreto, del deudor ${ }^{11}$. En un trabajo anterior, hemos sostenido que el dere-

\footnotetext{
${ }^{7}$ Cabe hacer presente que en el derecho estadounidense ha sido reconocida expresamente en el §2508 del Uniform Commercial Code (en adelante, UCC). Para una visión comparatista entre la CISG y el UCC, véase SCHNEIDER (1989).

${ }^{8}$ Schmitt (1982), p. 283.

${ }^{9}$ VIDAL (2009).

10 Para este tópico resulta ineludible la revisión de la monografía de: Mej́́As (2011).

11 Contardo (2014a).
} 
cho a la subsanación del cumplimiento no conforme antes del vencimiento del plazo constituye una posible medida del deudor para evitar, corregir o mitigar los efectos de un futuro incumplimiento contractual ${ }^{12}$. Tal como hemos propuesto, una de las formas de subsanación, la que denominaremos anticipatoria, permitiría al deudor evitar o bien mitigar las consecuencias del incumplimiento contractual, favoreciendo con ello también la conformidad contractual.

Para estos efectos, en primer lugar, trataremos de conceptualizar la regla del régimen de cumplimiento conforme de las obligaciones contractuales, base sobre la cual se desempeña la siguiente investigación (I). En segundo lugar, se describirá el tratamiento de la subsanación del cumplimiento en los instrumentos de derecho contractual uniforme, determinando sus clases y efectos (II). Por último, se tratará sobre la posible adopción de la figura en el derecho chileno de contratos, con referencia especial al derecho civil y de consumo (III).

\section{El sustrato: el régimen de conformidad en el cumplimiento de obligaciones contractuales como presupuesto de la subsanación del cumplimiento}

La base sobre la cual se desempeña el derecho del deudor para subsanar la prestación es el concepto de "conformidad" (conformity), o su opuesto, que es el de la "falta de conformidad" (lack of conformity).

Uno de los avances del nuevo derecho de la contratación es la centralización del concepto de incumplimiento, que se reúne fundamentalmente en dos figuras: la falta de entrega (en las obligaciones de dar) o falta en la de prestación (que incluye el incumplimiento total en las obligaciones de hacer y no hacer), y la falta de conformidad. Este segundo tipo de incumplimiento, en general, supone el cumplimiento de la prestación, pero de manera imperfecta (en un sentido amplio $)^{13}$.

Así, la falta de conformidad concentra un conjunto de incumplimientos que en los derechos de tradición europea-continental, y en especial de influjo francés, antes se encontraban diseminados (cumplimiento parcial, cumplimiento defectuoso o imperfecto, vicios redhibitorios, incluso el error) y que no necesariamente tenían las mismas respuesta por el ordenamiento objetivo (por lo menos para los países de la órbita europea continental $)^{14}$. Por ello, la

12 Contardo (2014a), pp. 558-561.

13 VAQUer (2011), p. 9.

14 KRÖlL (2011a), p. 492. 
virtud de la generación del concepto de falta de conformidad en el nuevo derecho de contratos es la reducción de estos diversos incumplimientos en una categoría única que facilita la aplicación de los medios de tutela del acreedor $^{15}$.

Pues bien, la noción de falta de conformidad coloca el énfasis en el incumplimiento de la obligación y, por lo tanto, en la operatividad de los medios de tutela. Al determinarse que la prestación no es conforme, le asisten al acreedor un conjunto de remedios que puede ejercer para satisfacer su interés.

Un primer acercamiento a la idea de falta de conformidad, implicaría estimar que su opuesto, la "conformidad", sería simplemente la otra cara de una misma moneda, de tal suerte que se podría hablar indistintamente de la conformidad o de la falta de ella. Sin embargo, nuestra opinión es que además de una opción lingüística, hay también una cuestión de acentos. La expresión "conformidad" lo coloca en el cumplimiento del contrato, y no en el incumplimiento, lo que denotaría la falta de ella. Determinar cuándo una prestación es conforme permite enfocarse en aquellas situaciones en las que no tienen operatividad los medios de tutela, o bien, puede evitarse su ejercicio. De esta manera, cuando se habla de un sistema que favorece la conformidad contractual, a lo que se alude es que el ordenamiento confiere mecanismos para evitar el ejercicio de los remedios, o bien, que los limita.

Así, el derecho del deudor a subsanar una prestación no conforme, se condice con un sistema que favorece la conformidad, y con ello se puede evitar, de manera total o parcial, el ejercicio de los principales medios de tutela.

Por esta razón, creemos conveniente describir las bases dogmáticas sobre las cuales se desempeña este derecho del deudor de corregir la prestación defectuosa. Para estos efectos describiremos, primero, la situación de la conformidad en los instrumentos de derecho contractual uniforme (1). Como se verá, en estos instrumentos hay un tránsito desde la idea de falta de conformidad hacia el de la conformidad. A continuación, determinaremos que la noción de conformidad se erige como una nueva idea rectora en el plano del nuevo derecho de la contratación, que de alguna manera la favorece tratando de evitar el ejercicio de los remedios (2).

${ }^{15}$ KRÖLL (2011a), p. 492. 


\section{De la falta de conformidad de la cosa en la compraventa internacional al cumplimiento conforme de la obligación: el tránsito desde la CISG hasta el resto de los instrumentos internacionales ${ }^{16}$}

\section{a. La CISG}

Para el estudio de la noción de falta de conformidad, un punto de partida puede colocarse en la $\mathrm{CISG}^{17}$. El art. 35 regula la (falta de) conformidad en los términos siguientes:

“(1) El vendedor deberá entregar mercaderías cuya cantidad, calidad y tipo correspondan a los estipulados en el contrato y que estén envasadas o embaladas en la forma fijada por el contrato.

(2) Salvo que las partes hayan pactado otra cosa, las mercaderías no serán conformes al contrato a menos:

a) que sean aptas para los usos a que ordinariamente se destinen mercaderías del mismo tipo;

b) que sean aptas para cualquier uso especial que expresa o tácitamente se haya hecho saber al vendedor en el momento de la celebración del contrato, salvo que de las circunstancias resulte que el comprador no confió, o no era razonable que confiara, en la competencia y el juicio del vendedor;

c) que posean las cualidades de la muestra o modelo que el vendedor haya presentado al comprador;

d) que estén envasadas o embaladas en la forma habitual para tales mercaderías o, si no existe tal forma, de una forma adecuada para conservarlas y protegerlas.

\footnotetext{
${ }^{16}$ De LA MAZA (2015) es el autor que en doctrina nacional se ha preocupado con mayor detención sobre el concepto de conformidad. En efecto, tal como el mismo autor reconoce (p. 80), la idea de conformidad (o de la falta de ella) es un tópico que hasta la fecha ha sido más bien inexplorado. Quizás con la notable excepción de VIDAL (2006), quien fue el primero en hacer alusión a la construcción de un sistema basado en una categoría amplia y aglutinadora de los incumplimientos. Ahora bien, el trabajo de De LA MAZA, como también lo reconoce el mismo autor, es más bien exploratorio del concepto. En el apartado que sigue nosotros abarcaremos un aspecto distinto del abordado por el autor recién mencionado. En dicho trabajo, el autor enfoca en el concepto de conformidad, como una categoría que engloba variados incumplimientos como la falta de la adecuación material de la cosa, en la compraventa, a las exigencias esperadas de la misma. En cambio, nuestra aproximación se refiere a la idea que la conformidad que envuelve un favorecimiento del interés del acreedor a través de medios alternativos para racionalizar el ejercicio de los remedios contractuales. De aquí que aunque los dos trabajos (el citado y el presente) tengan algunos puntos de contacto (por ejemplo, en materia de análisis del art. 35 CISG) apuntan a objetivos distintos.

17 Los antecedentes directos de la disposición son los arts. 19(1), 33(1) y 36 ULIS. Sin embargo, tal como expone KRöLL, la disposición de Viena tiene variaciones sustanciales con su antecedente. Confróntese, KRÖLL (2011a), p. 490.
} 
(3) El vendedor no será responsable, en virtud de los apartados a) a d) del párrafo precedente, de ninguna falta de conformidad de las mercaderías que el comprador conociera o no hubiera podido ignorar en el momento de la celebración del contrato".

El apartado (1) establece que las mercaderías deben ajustarse a los parámetros establecidos en el contrato desde, a falta de estipulación (véase el encabezado del art. 35[2] CISG), cuatro perspectivas: cantidad, calidad y envase o embalaje. A contrario sensu, una mercadería entregada que no cumpla con los estándares contractuales, entonces debe ser considerada como no conforme. De esta manera, el art. 35(2) en todas sus letras detalla cuándo en específico habría entrega no conforme.

Sin entrar al detalle de las causales, lo cierto es que el detallado art. 35(2) CISG está enfocado en las causales precisas de disconformidad, estableciendo estándares de conformidad que se presumen a menos que las partes hayan pactado otra $\operatorname{cosa}^{18}$. De ahí que el acreedor es quien debe dar noticia al vendedor de la disconformidad de acuerdo con el art. 39 CISG, luego de haber inspeccionado las mercaderías y poder descubrir la disconformidad. Es decir, sin noticia, el riesgo de la falta de conformidad (nos referimos al riesgo del incumplimiento) lo sufre el comprador, quien debe evidenciárselo al vendedor. En efecto, la falta de noticia priva al acreedor de su derecho a reclamar remedios ${ }^{19}$.

La clave frente a la falta de conformidad, a partir del art. 35 CISG, es que cualquiera disconformidad entre lo pactado y lo entregado (o no entregado ${ }^{20}$, supone un supuesto de incumplimiento amplio, que subsume todas las categorías antes expuestas bajo una fórmula simple y efectiva: si no se cumple lo pactado, hay lugar al ejercicio de los remedios ${ }^{21}$. De aquí es que puede sostenerse que la falta de conformidad, por lo menos en la CISG, es la falta de adecuación material de la cosa al contrato ${ }^{22}$. Con todo, no todos los incumplimientos, atendida su gravedad, ofrecen toda la gama de remedios disponibles al acreedor. Los más graves se ofrecen con mayor disposición al acreedor; y los menos graves, alternativas reducidas.

18 KRÖLL (2011a), p. 505.

19 DiMatteo y otros (2005), pp. 84-91; KRÖll (2011c), p. 619.

${ }^{20}$ O como lo grafica VIDAL, entre el objeto ideal y real: VIDAL (2009), pp. 44-48.

${ }^{21}$ KRÖLL (2011a), pp. 491-492.

22 De la Maza (2015). 


\section{b. Los demás instrumentos de unificación contractual}

En los demás instrumentos podemos distinguir dos modelos. Uno, que sigue de alguna manera la noción de falta de conformidad en atención al incumplimiento; y un segundo, que acentúa la necesidad de que la prestación para estimarse cumplida sea conforme al contrato.

\section{i. Los que colocan el acento en el incumplimiento}

En los PICC la situación es bien similar a la CISG, pero se configura la falta de conformidad de manera más amplia. Así, el art. 7.1.1. PICC, define incumplimiento sin aludir expresamente a la falta de conformidad: "El incumplimiento consiste en la falta de ejecución por una parte de alguna de sus obligaciones contractuales, incluyendo el cumplimiento defectuoso o el cumplimiento tardío". Tal como opina un comentarista del texto de Unidroit, la redacción se debe a que ellos tienen la aspiración de ser aplicados a cualquier tipo de contratos. De esta manera, se justificaría la redacción más amplia que la CISG que está circunscrita a la compraventa ${ }^{23}$.

La cristalización de esta idea más amplia se confirma en los PECL. De manera muy similar, se define incumplimiento en el art. 1:301(4): "Non performance' denotes any failure to perform an obligation under the contract, whether or not excused, and includes delayed performance, defective performance and failure to cooperate in order to give full effect to the contract". Los comentaristas de la disposición dan cuenta que tras el concepto de incumplimiento de los PECL se envuelve la misma idea de falta de conformidad en los PICC ${ }^{24}$.

Si miramos comparativamente la CISG, los PICC y los PECL el acento de todas estas normas está en el incumplimiento. En otras palabras, las tres disposiciones tratan de establecer, con mayor o menor detalle, cuándo el deudor no cumple con la prestación.

\section{ii. Los que colocan el acento en la conformidad}

La situación es sutilmente diversa en el DCFR y en la CESL. En estos instrumentos el acento ya no se coloca en el incumplimiento, sino cuando se satisface el interés del acreedor. En este sentido, es posible observar un tránsito desde el DCFR hacia la CESL.

Así, el DCFR, en su art. III.-1:102(3), define incumplimiento de una manera idéntica a los PICC y PECL: "Non-performance of an obligation is any failure

23 SChelhats (2009), p. 734.

${ }^{24}$ Dízz-Picazo y otros (2002), pp. 321-322. 
to perform the obligation, whether or not excused, and includes delayed performance and any other performance".

Sin embargo, el art. VI.A.- 2:301 (relativo a la compraventa) transita hacia una noción más allá de la "falta de conformidad" hacia la "conformidad". De esta manera, establece que las mercaderías no serán conformes al contrato a menos que:

"(a) are of the quantity, quality and description required by the contract;

(b) are contained or packaged in the manner required by the contract;

(c) are supplied along with any accessories, installation instructions or other instructions required by the contract; and

(d) comply with the remaining Articles of this Section".

Si se observa bien, lo que interesa a este respecto no es la adecuación estricta de la prestación al programa ideal, como parece sugerirse del art. III.-1:102(3), sino que la prestación cumpla, a lo menos, ciertas características mínimas a falta de estipulación de las partes.

Esto, a nuestro entender, se ve corroborado por el art. 99 CESL:

"Conformidad con el contrato

1. Para estar en conformidad con el contrato, los bienes o los contenidos digitales deberán:

(a) ser de la cantidad, calidad y tipo estipulados en el contrato;

(b) estar envasados o embalados en la forma estipulada por el contrato; y

(c) ser suministrados con los accesorios, instrucciones de instalación u de otro tipo estipulados por el contrato.

2. Para estar en conformidad con el contrato, los bienes o los contenidos digitales deberán asimismo satisfacer los requisitos de los artículos 100, 101 y 102, salvo en la medida que las partes hayan acordado otra cosa.

3. En un contrato de compraventa de bienes de consumo, cualquier acuerdo que establezca excepciones a la aplicación de los requisitos de los artículos 100, 102 y 103 en detrimento del consumidor sólo será válido si, en el momento de la celebración del contrato, el consumidor conocía las condiciones específicas de los bienes o los contenidos digitales y los aceptó como conformes con el contrato en el momento de su celebración.

4. En contratos de compraventa de bienes de consumo, las partes no podrán excluir la aplicación del apartado 3, ni introducir excepciones o modificar sus efectos en detrimento del consumidor". 
Si se observa bien, la CESL reincide en la expresión "conformidad", antes de la falta de ella. Nos da la impresión que aquí la utilización de la expresión "conformidad" denota que lo que importa más allá del cumplimiento estricto de la prestación, es que ella cumpla los fines establecidos por la norma ${ }^{25}$ : el mantenimiento de la cantidad, calidad y tipo, de acuerdo al envase pactado y ser suministrado con los accesorios correspondientes, aun cuando la prestación cumplida no sea exactamente la pactada.

Algunos fallos de Viena confirman esta posición a pesar del tenor del art. 35(2) CISG, que parece ser un tanto más estricto que los últimos dos mencionados $^{26}$. Así, en la compraventa de maquinaria, autos y software se ha fallado que hay algunos problemas de puesta en marcha que son comunes y previsibles en contratos de esta especie y no denotan una falta de conformidad en sí misma. Lo mismo sucede cuando se envían mercaderías en grandes cantidades, y pocas de ellas tienen defectos menores. Incluso, se ha fallado en el envío de catálogos que tienen problemas de impresión en una de las líneas, pero permiten su perfecto entendimiento, que no constituyen incumplimiento. A pesar de que en todos los casos es posible entender que hay falta de conformidad en el fondo se ha estimado que estos incumplimientos menores no constituyen un incumplimiento relevante en atención a la prestación. De esta manera, es posible sostener que se favorece la conformidad y se evita de alguna manera el ejercicio de los remedios relacionados con ella, como se pasará a explicar.

\section{La noción de conformidad (o de su falta) y su incardinación en un sistema de remedios que favorecen los medios de tutela orientados al cumplimiento}

La noción de falta de conformidad se encuentra en estrecha relación con la idea de un sistema de remedios por incumplimiento contractual. En otras palabras, no es posible construir un concepto tan amplio de incumplimiento que no permita distintas acciones y remedios a favor del acreedor.

Ello se debe a dos razones. La primera, es que la noción de falta de conformidad está en íntima vinculación con la de un incumplimiento que admite distintas intensidades, de tal suerte que el ordenamiento no debiera siempre reaccionar de la misma manera ante cualquier desviación del programa contractual. Así, en la misma CISG surge la noción de incumplimiento fundamental. Sólo en virtud del incumplimiento más grave, el incumplimiento esencial, se permite el ejercicio del remedio más radical, cual es la resolución del contrato,

25 Zoll (2012a), p. 465.

26 Para las líneas que siguen nos hemos valido de los ejemplos jurisprudenciales colocados por: SAIDOV (2015), p. 133. 
y que permite la extinción del vínculo contractual siempre que este remedio satisfaga los intereses del acreedor ${ }^{27}$. Pero en los demás casos, es decir, cuando el incumplimiento no revista la gravedad suficiente para permitir la extinción de la relación obligatoria, se abren otros remedios alternativos que también permiten la satisfacción del interés del acreedor, dentro de los cuales se encuentra la subsanación del incumplimiento ${ }^{28}$.

La segunda razón relativa a que la noción de falta de conformidad está relacionada con la idea de un sistema de remedios es que al tener distintos requisitos de operatividad, permiten la satisfacción del interés del acreedor de manera alternativa al cumplimiento. Estos son los remedios que Vanessa MAK denomina "orientados al cumplimiento" (performance-oriented remedies) ${ }^{29}$.

En todo este marco remedial, se produce una suerte una tensión entre los intereses del acreedor y del deudor. Si bien los distintos remedios intentan satisfacer el interés del acreedor, en aras de mantener el equilibrio contractual y favorecer el cumplimiento del contrato, se generan posibilidades al deudor para evitar la resolución en las situaciones de incumplimiento más graves; y en las menores, para satisfacer alternativamente el interés del acreedor. Algunas de éstas están relacionadas con un cumplimiento alternativo de la prestación o su sustitución en dinero (la reparación, la sustitución y la corrección del cumplimiento); y otras están relacionadas con un cumplimiento tardío de la prestación en naturaleza (el cumplimiento dentro del plazo adicional y, también, la corrección del cumplimiento) ${ }^{30}$. El remedio que siempre compensa estas medidas alternativas es la indemnización de perjuicios.

Desde luego, un incumplimiento total y definitivo permitiría al acreedor solicitar el cumplimiento del contrato, pues éste es esencial en atención a su magnitud (aunque no lo será siempre en relación al plazo, como se mencionara posteriormente). Pero cuando el incumplimiento del contrato no es esencial en atención a la prestación, bien cabe cuestionarse sobre la pertinencia de la totalidad de los remedios.

Es en este punto en el que radica la idea de corrección del incumplimiento. Hay ciertos incumplimientos que no deben por qué ser reconducidos siempre a los incumplimientos esenciales en atención a su magnitud. De esta

\footnotetext{
27 En Chile, véase VIDAL (2006), pp. 96 y ss.

28 BJÖRKLUND (2011), pp. 348-349.

29 La autora dedica toda una monografía a ellos: MAK (2009), distinguiendo entre el cumplimiento en naturaleza (specific performance (pp. 77-114), reparación y sustitución (repair and replacement) (pp. 115-148) y corrección del cumplimiento (right to cure) (pp. 149-186).
}

30 La distinción ha sido tomada de MAK (2009), p. 57. 
suerte, es posible que se le otorgue una segunda oportunidad al acreedor para cumplir.

Pues bien, una de estas medidas es la corrección del incumplimiento, la que será analizada en las líneas que siguen.

\section{La corrección del cumplimiento en los instrumentos de derecho contractual uniforme (right to cure) como medida facilitadora de la conformidad contractual}

Tal como se señaló, uno de los remedios que favorece el cumplimiento de los contratos es, precisamente, la corrección del cumplimiento, objeto del presente trabajo. Adelantamos que la corrección del cumplimiento sirve en el derecho uniforme de contratos para enervar, incluso, la facultad resolutoria.

El interés por la institución surge de la idea del porqué el acreedor debiera soportar que el deudor cumpla, normalmente fuera del plazo inicialmente pactado, una obligación que en un primer momento debió haber sido satisfecha en tiempo y forma. ¿ No debiera el acreedor tener derecho para solicitar cualquiera de sus remedios disponibles, incluso la resolución? O, por otra parte, ¿cuáles son las razones que permitirían al acreedor solicitar la corrección de un cumplimiento no conforme?

En este sentido, Vanessa MAK concluye que las medidas orientadas al cumplimiento, dentro de las cuales se encuentra por cierto la corrección, se basan fundamentalmente en la idea de la eficiencia económica. Así, cuando resulta más eficiente corregir o subsanar antes que satisfacer el interés del acreedor de otra manera -a través de la resolución en su versión más radical- deben preferirse estas medidas orientadas al cumplimiento antes de las alternativas ${ }^{31}$. En el fondo, lo que se trata de evitar es que el remedio sea peor que la enfermedad desde el plano económico. Y esta parece ser la idea que subyace a la CISG y al resto de los instrumentos de derecho contractual uniforme, según analizaremos a continuación.

\section{El reconocimiento del derecho del deudor para corregir o subsanar el cumplimiento no conforme en los diversos instrumentos de derecho contractual uniforme}

Para los efectos del análisis de los respectivos instrumentos, creemos conveniente describir el panorama de la CISG (a) que es el punto de partida de los demás instrumentos de unificación contractual (b, c y d).

${ }^{31}$ MAK (2009), pp. 74-75. 


\section{a. El punto de partida: Arts. 34, 37 y 48 CISG}

El derecho subsanación del cumplimiento por el deudor tiene su moderna configuración en la CISG y, a partir de ahí, ha sido reformado en el resto de los instrumentos internacionales ${ }^{32}$.

La Convención reconoce en tres artículos la posibilidad que el deudor pueda subsanar el cumplimiento. Sin embargo, la institución debe analizarse sólo desde dos puntos de vista, pues las facetas de la institución, a pesar de que están diseminadas en tres artículos, en realidad, tienen dos vertientes: la subsanación anticipatoria (arts. 34 y 37 CISG) y la normal o corriente, que tiene lugar después del vencimiento del plazo (art. 48 CISG). El criterio de distinción está relacionado con el plazo para el cumplimiento de la obligación. Cuando la subsanación se realiza antes de la llegada del plazo, la calificaremos de anticipatoria; en cambio, cuando la subsanación se realiza con posterioridad a su vencimiento, será la normal o corriente.

La explicación de estas instituciones nos permitirá analizar los demás instrumentos que constituyen evoluciones del texto de la Convención de Viena.

\section{i. Subsanación anticipatoria}

Tal como se introdujo, la subsanación anticipatoria se produce antes de la llegada del plazo.

En la CISG, como parte de la base de un traslado de las mercaderías de un lugar a otro y, por lo tanto, el cumplimiento de la obligación no es puro y simple sino a plazo, el supuesto con el cual se han configurado las reglas es que el vendedor haya despachado las mercaderías y antes de la entrega descubre que la mercadería o los documentos representativos de ella adolecen de una falta de conformidad.

\footnotetext{
${ }^{32}$ Con todo, debe reconocerse que el antecedente del art. 34 CISG es el art. 51 ULIS: "If the seller fails to hand over documents as provided in Article 50 at the time and place fixed or if he hands over documents which are not in conformity with those which he was bound to hand over, the buyer shall have the same rights as those provided under Articles 24 to 32 or under Articles 41 to 49, as the case may be". Asimismo, también ya estaba consagrada en el Uniform Commercial Code, § 2-508: "Cure by Seller of Improper Tender or Delivery; Replacement.

(1) Where any tender or delivery by the seller is rejected because non-conforming and the time for performance has not yet expired, the seller may seasonably notify the buyer of his intention to cure and may then within the contract time make a conformingdelivery.

(2) Where the buyer rejects a non-conforming tender which the seller had reasonable grounds to believe would be acceptable with or without money allowance the seller may if he seasonably notifies the buyer have a further reasonable time to substitute a conforming tender".
} 
Sobre esta base, los supuestos de hecho que tipifica la CISG son dos: (1) el envío anticipado de mercadería no conforme, y (2) los títulos de las mercaderías adolecen de falta de conformidad. Veamos los casos.

(1) En el caso de entrega anticipada el art. 37 CISG dispone:

"En caso de entrega anticipada, el vendedor podrá, hasta la fecha fijada para la entrega de las mercaderías, bien entregar la parte o cantidad que falte de las mercaderías o entregar otras mercaderías en sustitución de las entregadas que no sean conformes, bien subsanar cualquier falta de conformidad de las mercaderías entregadas, siempre que el ejercicio de ese derecho no ocasione al comprador inconvenientes ni gastos excesivos. No obstante, el comprador conservará el derecho a exigir la indemnización de los daños y perjuicios conforme a la presente Convención" ${ }^{\prime 33}$.

En virtud de este artículo, la mercadería es recibida por el comprador antes del vencimiento del plazo (art. $33 \mathrm{CISG}$ ), pues se produce la "entrega anticipada" ${ }^{34}$. Sin embargo, el deudor detecta que la entrega de las mercaderías no ha sido conforme al contrato según el parámetro del artículo 35, y se le confiere el derecho para que subsane las mercaderías. La subsanación consistirá ya en completar lo faltante, reparar lo defectuoso o sustituir nuevas mercaderías, si ello es necesario. La norma es amplia y no limita la subsanación a una medida concreta ${ }^{35}$.

La limitación de este derecho del deudor está en que la subsanación de la mercadería no conforme "no ocasione al comprador inconvenientes ni gastos excesivos".

Sin perjuicio de que el deudor subsane la mercadería no conforme, al acreedor todavía le asiste el derecho para reclamar la indemnización de perjuicios por todo aquello que no fuere cubierto por la subsanación.

(2) Por otra parte, el art. 34 CISG establece la subsanación anticipatoria cuando la entrega de los documentos relacionados con las mercaderías no es conforme:

"El vendedor, si estuviere obligado a entregar documentos relacionados con las mercaderías, deberá entregarlos en el momento, en el lugar y en la forma fijados por el contrato. En caso de entrega anticipada de documen-

\footnotetext{
${ }^{33}$ En el derecho estadounidense, el paralelo de este artículo se encuentra en \$2-508(1) UCC: "Where any tender or delivery by the seller is rejected because non-conforming and the time for performance has not yet expired, the seller may seasonably notify the buyer of his intention to cure and may then within the contract time make a conforming delivery".

34 HonNold (1999), p. 267; KRÖll (2011b), p. 551.

35 KRÖLL (2011b), p. 555.
} 
tos, el vendedor podrá, hasta el momento fijado para la entrega, subsanar cualquier falta de conformidad de los documentos, si el ejercicio de ese derecho no ocasiona al comprador inconvenientes ni gastos excesivos. No obstante, el comprador conservará el derecho a exigir la indemnización de los daños y perjuicios conforme a la presente Convención".

Tal como suscribe la doctrina, el art. 34 es la extensión natural del art. 30 $\mathrm{CISG}^{36}$, que obliga al vendedor no sólo a la entrega de la cosa, sino a los documentos relacionados con la mercadería y que permitan la transferencia de la propiedad de la misma.

A pesar de que la disposición ha sido criticada por su redacción ${ }^{37}$, permite entender que cuando se ha pactado transporte, un conjunto de documentación puede ser exigida, tal como el conocimiento de embarque, factura de las mercaderías enviadas, pólizas de seguro contratadas, etc. ${ }^{38}$. Así, si hay entrega anticipada de la documentación, y ésta no es conforme, podría el deudor subsanarla, con la misma limitación descrita anteriormente ("si el ejercicio de ese derecho no ocasiona al comprador inconvenientes ni gastos excesivos ${ }^{139}$ ).

Finalmente, es necesario señalar que los autores parecen estar contestes que el art. 34 debe ejercerse en los mismos términos del art. 37, de tal suerte que está sujeto a las mismas limitaciones establecidas en dicho artículo, a pesar de que la Convención no hace el reenvío directo a la norma ${ }^{40}$.

\section{ii. Subsanación después del vencimiento del plazo o regular}

Esta clase de subsanación está regulada en la CISG de manera separada de la anticipatoria. Su característica esencial es que la subsanación se produce después de la entrega no conforme. En esta situación la entrega es oportuna, o incluso anticipada, por lo que no hay en principio retraso. De esta manera, lo importante es que incumplimiento se califique en atención a la cosa misma y no al tiempo previsto para la ejecución del contrato.

\footnotetext{
36 Honnold (1999), p. 237.

37 Honnold (1999), p. 237; LANDO (1987), p. 267.

38 LANDo (1987), p. 266; Widmer (2010), p. 561; Plitz (2011), p. 466. Por otra parte, los documentos técnicos de la cosa, como diagramas de circuitos, instrucciones de instalación u otros de similar naturaleza, no están incorporados en la disposición, ya que ellos son considerados como parte de la cosa de conformidad con el art. 35(2)(a): PLITz (2011), p. 476.
}

${ }^{39}$ Apunta BRIDGe (2013), p. 584, que esta limitación en materia de documentos permitiría la distinción entre compradores y compradores intermediarios, pues la entrega documentaria conforme es especialmente sensible para los segundos.

${ }^{40}$ LANDO (1987), p. 267; HONNOLD (1999), p. 237; KRÖLl (2011b), p. 552. 
La Convención regula esta forma de subsanación en su art. 48, que creemos conveniente reproducir:

“1) Sin perjuicio de lo dispuesto en el artículo 49, el vendedor podrá, incluso después de la fecha de entrega, subsanar a su propia costa todo incumplimiento de sus obligaciones, si puede hacerlo sin una demora excesiva y sin causar al comprador inconvenientes excesivos o incertidumbre en cuanto al reembolso por el vendedor de los gastos anticipados por el comprador. No obstante, el comprador conservará el derecho a exigir la indemnización de los daños y perjuicios conforme a la presente Convención.

2) Si el vendedor pide al comprador que le haga saber si acepta el cumplimiento y el comprador no atiende la petición en un plazo razonable, el vendedor podrá cumplir sus obligaciones en el plazo indicado en su petición. El comprador no podrá, antes del vencimiento de ese plazo, ejercitar ningún derecho o acción incompatible con el cumplimiento por el vendedor de las obligaciones que le incumban.

3) Cuando el vendedor comunique que cumplirá sus obligaciones en un plazo determinado, se presumirá que pide al comprador que le haga saber su decisión conforme al párrafo precedente.

4) La petición o comunicación hecha por el vendedor conforme al párrafo 2) o al párrafo 3) de este artículo no surtirá efecto a menos que sea recibida por el comprador" ${ }^{\prime 4}$.

Como se puede apreciar, la norma expuesta regula dos situaciones. La primera, establecida en el primer apartado, que permite el vendedor/deudor subsanar el incumplimiento cumpliéndose ciertas condiciones.

El derecho a subsanar es amplio, y cubre la mayoría de los incumplimientos, ya sea la falta de conformidad de la cosa, defectos en los títulos, retraso, entrega parcial, etc. ${ }^{42}$. Lo importante para dar aplicación a la norma, es que la falta de conformidad sea posible de subsanar ${ }^{43}$. De esta manera, si el plazo

\footnotetext{
${ }^{41}$ Su espejo en el UCC estadounidense se encuentra en el §2-508(2): "Where the buyer rejects a nonconforming tender which the seller had reasonable grounds to believe would be acceptable with or without money allowance the seller may if he seasonably notifies the buyer have a further reasonable time to substitute a conforming tender".

42 Müllen-Chen (2010), pp. 734-735.

43 Müllen-Chen (2010), pp. 735-736.
} 
es esencial, o la subsanación demorará más allá de lo razonable, se pierde el derecho a la subsanación, lo que dependerá de cada caso ${ }^{44}$.

Esta es la razón por la que existe una estrecha vinculación entre el right to cure con la resolución del contrato (y el sistema adoptado para su ejercicio por la CISG). La expresión "Sin perjuicio de lo dispuesto en el artículo 49" denota que el ejercicio de la subsanación por el deudor evita que el acreedor haga uso de su facultad resolutoria, a través de la notificación unilateral establecida en el art. $49 \mathrm{CISG}^{45}$. Asimismo, tal como apunta BRIDGE, la norma es consistente con la resolución por anticipación regulada en el artículo 72 CISG, que impone al deudor que quiere la carga de asegurar debidamente la prestación si quiere evitar la resolución ${ }^{46}$.

La segunda forma de subsanación, regulada en los apartados (2) a (4), establece la situación de retraso en el cumplimiento de la obligación, o bien, de noticia por parte del comprador que la cosa no es conforme al contrato. En tal situación, el vendedor puede mostrarse llano a cumplir con retraso o subsanar la prestación defectuosa, y manifestárselo al comprador. El comprador entonces podría aceptar la subsanación, o bien, declarar el contrato resuelto, siempre que se haya producido un incumplimiento esencial del contrato (fundamental breach). En este segundo supuesto, la CISG le otorga valor al silencio del comprador, en el sentido de que si no rechaza la propuesta de subsanación o de cumplimiento retrasado, puede el deudor cumplir en el plazo adicional ofrecido, siempre que éste sea razonable.

\section{b. La evolución: Art. 7.1.4. PICC}

La configuración de los PICC es un tanto distinta a la efectuada en la CISG y podríamos decir que constituye, en cierta medida, una evolución del texto de la compraventa internacional. Parte de estas diferencias resulta del hecho que los PICC tienen intención de aplicarse a cualquier tipo de obligación y no sólo a la compraventa ${ }^{47}$.

Para el análisis de esta disposición, creemos pertinente reproducir el texto respectivo:

\footnotetext{
${ }^{44}$ Huber (2011b), pp. 713-714.

${ }^{45}$ LIU (2005). Cabe anotar que la disposición en el texto en idioma inglés no es idéntica al español. Comienza el art. 48 en inglés prescribiendo "Subject to article 49", lo que podría dar lugar a sostener que la subsanación depende del ejercicio del remedio resolutorio.

46 BRIDGe (2013), p. 584.

47 En el mismo sentido: KeE (2004).
} 


\section{"(Subsanación del incumplimiento)}

(1) La parte incumplidora puede subsanar a su cargo cualquier incumplimiento, siempre y cuando:

(a) notifique sin demora injustificada a la parte perjudicada la forma y el momento propuesto para la subsanación;

(b) la subsanación sea apropiada a las circunstancias;

(c) la parte perjudicada carezca de interés legítimo para rechazarla; y

(d) dicha subsanación se lleve a cabo sin demora.

(2) La notificación de que el contrato ha sido resuelto no excluye el derecho a subsanar el incumplimiento.

(3) Los derechos de la parte perjudicada que sean incompatibles con el cumplimiento de la parte incumplidora se suspenden desde la notificación efectiva de la subsanación hasta el vencimiento del plazo para subsanar.

(4) La parte perjudicada puede suspender su propia prestación mientras se encuentre pendiente la subsanación.

(5) A pesar de la subsanación, la parte perjudicada conserva el derecho a reclamar el resarcimiento por el retraso y por cualquier daño causado o que no pudo ser evitado por la subsanación".

Lo primero que salta a la vista de la disposición es que no se regula de forma separada la subsanación anticipatoria de la que se produce con posterioridad al vencimiento del plazo de entrega. Sin embargo, alguna doctrina entiende que cubre ambos supuestos ${ }^{48}$.

Una segunda cuestión que destaca de la disposición es que la norma es bastante más limitativa que la CISG. Aclara la norma que la subsanación debe ser propuesta por el deudor sin demora injustificada; la proposición debe contener una solución "apropiada a las circunstancias", y que la efectiva subsanación se practique de manera rápida. Asimismo, el acreedor no puede rechazar la oferta, a menos que tenga un legítimo interés en que la subsanación no se lleve a efecto. En este sentido, los comentarios oficiales a los PICC establecen que la pura voluntad de resolver el negocio no es suficiente como "legítimo interés"

\footnotetext{
48 KRUISINGA (2011), p. 913. Cabe hacer presente que los comentarios oficiales a los PICC no contienen una referencia especial a la subsanación anticipatoria: Unidroit (2010), pp. 226-230.
} 
del acreedor. El ejemplo que dan los comentarios es que el acreedor puede argumentar que la subsanación le puede causar aún más daño ${ }^{49}$.

Por último, los PICC regulan de manera expresa el derecho del deudor a subsanar la prestación, aun cuando se haya practicado la resolución unilateral del contrato, lo que ha recibido la crítica que la disposición no ayuda a dar certeza al futuro de la relación contractual ${ }^{50}$.

\section{c. La regla sintética: Art. 8:104 PECL}

Los PECL, con una regla muy sintética, regulan el derecho del acreedor a la subsanación del cumplimiento no conforme en su artículo 8:104:

"A party whose tender of performance is not accepted by the other party because it does not conform to the contract may make a new and conforming tender where the time for performance has not yet arrived or the delay would not be such as to constitute a fundamental non-performance".

Es muy probable que la reducción de la regla se deba a que está redactada en clave de principios, más a la de un texto con pretensiones de codificación (como lo es el DCFR y la CESL que se revisarán en seguida), y de ahí que su redacción no regule con toda exhaustividad sus requisitos y efectos. De la misma manera, los comentarios oficiales a la disposición son breves y se limitan prácticamente a dar tres ejemplos ${ }^{51}$.

Con todo, los Principios sí aclaran que la subsanación sólo tiene aplicación cuando el plazo se torna en esencial por la concesión de un plazo adicional para el cumplimiento (art. 8:106 PECL) ${ }^{52}$.

La aclaración tiene interés, puesto que la subsanación no debe analizarse al margen del ejercicio de la resolución por el acreedor. Tanto en la CISG como en el resto de los instrumentos de derecho contractual uniforme el acreedor que ejerce la resolución puede otorgar un plazo adicional para que el deudor cumpla. Aquí no nos encontramos necesariamente en el caso de una falta de conformidad menor, sino en los casos en que el incumplimiento, cualquiera sea su naturaleza, sea fundamental o esencial. El punto es que si el acreedor está dudoso que el incumplimiento es esencial $-y$, por tanto, corre riesgo que la resolución esté mal ejercida, como puede suceder en los casos de falta de conformidad-, le puede otorgar un plazo adicional para el cumplimiento, y

\footnotetext{
${ }^{49}$ Unidroit (2010), p. 228.

50 Lui (2006); SchelhaAs (2009), p. 751.

51 Lando y Beale (2000), p. 368.

52 Lando y Beale (2000), p. 368.
} 
vencido el plazo sin el cumplimiento se le otorga el derecho para ejercer la resolución, sin que pueda recalificarse el incumplimiento como no esencial. En otras palabras, el vencimiento del plazo suplementario otorga el derecho para ejercer la resolución al arbitrio del deudor.

En la jurisprudencia de la CISG, el otorgamiento de este plazo adicional para el cumplimiento se ha considerado en la práctica como un requisito necesario para ejercer la resolución, pues si el acreedor no lo otorga, la carga de la prueba de la esencialidad del incumplimiento recae en el acreedor ${ }^{53}$, lo que implícitamente parece ser recogida por los PECL.

En consecuencia, el comentario de la norma de los PECL ayuda a entender un aspecto adicional de la institución en análisis: el derecho a subsanar está en íntima relación con el plazo adicional para el cumplimiento, puesto que cuando el acreedor haya ejercido la resolución y haya otorgado el plazo adicional para el cumplimiento, la subsanación debe tener lugar dentro del mismo plazo. Por el contrario, si la resolución es rechazada, entonces le asistía al deudor un verdadero derecho para cumplir dentro de plazo.

Por último, y antes de avanzar con el DCFR, queremos hacer presente que aunque los PECL, en su reducida redacción, distinguen brevemente entre subsanación anticipatoria y corriente ("where the time for performance has not yet arrived"), hay también una regulación particularizada en los Principios Europeos de Contratos de Servicios (PEL SC, que no es más que la concretización de los PECL al área de los servicios ${ }^{54}$ ), en su artículo 1:103(1) (c). Este artículo establece el deber precontractual del prestador del servicio de dar aviso al cliente de que el servicio puede tomar más tiempo que lo que razonablemente espera el cliente ${ }^{55}$. En estos casos, cuando el cliente no fue debidamente avisado antes de la celebración del contrato, podría tener lugar el cambio del servicio bajo el art. 1:111 PEL SC, siempre que el cambio (la subsanación) interese todavía al cliente, y éste en todo caso mantiene su derecho a reclamar por los daños sufridos, en conformidad al art. 1:103(3) (b) ${ }^{56}$. Así, de esta manera, para que tenga lugar el cambio del servicio el deudor debe notificar al cliente de la circunstancia de la falta de aviso, y proponer entonces la subsanación.

\footnotetext{
53 HUber (2011a), p. 709.

${ }^{54}$ Los PEL SC son fruto del esfuerzo académico del Study Group on a European Civil Code como una particularización de los PECL a un área específica del derecho de los contratos: los contratos de servicios. Véase: BARENDRECHT (2007), pp. xv-xvi.

55 BarendReCHt Y otros (2007), pp. 163 y ss.

${ }^{56}$ BARENDRECHT Y otros (2007), pp. 260-265.
} 


\section{d. Las reglas más desarrolladas: los artículos III.-3:302 DCFR y 109 CESL i. DCFR}

Por su parte, el DCFR regula la subsanación en cinco artículos (III.- 3:201 a III.- 3:205), estableciendo el primero sólo su ámbito de aplicación a los incumplimientos no conformes. De esta manera, los cuatro siguientes le otorgan contenido sustantivo.

Cabe hacer presente que la redacción del DCFR está pensada para cualquier tipo de incumplimiento, al estilo de lo que sucede en los PICC y PECL, pero con un marcado matiz codificado, a diferencia de los PECL. Por lo tanto, hasta la fecha, ésta parece ser la regulación más completa por los instrumentos de derecho contractual uniforme.

Las reglas generales son establecidas en el artículo III.- 3:20257. La novedad de este texto frente a los PECL y PICC es que regula la subsanación anticipatoria y la regular con más detalle.

Así, tratándose de la anticipatoria, el deudor tiene derecho a subsanar si cumple la prestación de manera no conforme y anticipadamente, de manera bastante similar al art. $37 \mathrm{CISG}^{58}$.

Por su parte, la subsanación regular del DCFR tiene algunas particularidades:

(a) Se expresa que el costo de la subsanación será asumida por el propio deudor (art. III.- 3:202[b]);

(b) El único remedio disponible para el acreedor es la suspensión del cumplimiento mientras esté pendiente el plazo para la subsanación (art. III.- 3:202 [b]);

(c) Se detallan los casos en que el acreedor puede no otorgarle la oportunidad al deudor para subsanar el incumplimiento (art. III.- 3:203): (i) cuando el plazo es esencial; (ii) el acreedor tiene razones para creer que la falta de conformidad se produjo bajo el conocimiento del deudor y el cumplimiento no se efectuó de acuerdo a la buena fe; (iii) el acreedor tiene razones para creer que la

57 "III.- 3:202: Cure by debtor: general rules

(1) The debtor may make a new and conforming tender if that can be done within the time allowed for performance.

(2) If the debtor cannot make a new and conforming tender within the time allowed for performance but, promptly after being notified of the lack of conformity, offers to cure it within a reasonable time and at the debtor's own expense, the creditor may not pursue any remedy for non-performance, other than withholding performance, before allowing the debtor a reasonable period in which to attempt to cure the nonconformity.

(3) Paragraph (2) is subject to the provisions of the following Article".

${ }^{58}$ Sin embargo, tal como nos da cuenta Tomás, los comentarios oficiales del DCFR son favorables a la subsanación anticipatoria, siempre que no se lesionen los intereses del acreedor, lo que es una diferencia con la CISG. TomÁs (2012), pp. 593-594, n. 5. 
prestación no podrá ser subsanada en un tiempo razonable y sin inconvenientes para el acreedor o perjuicio a los intereses del acreedor, y (iv) la subsanación sería inapropiada de acuerdo a las circunstancias. Se observa en todos estos casos que el DCFR con estas causales, en extremo amplias, limitan bastante la facultad del deudor para subsanar el cumplimiento no conforme ${ }^{59}$. Así parece ser que el DCFR es algo renuente a esta facultad, lo que no se condice con el tratamiento de la materia en los PECL.

(d) Trata con precisión las consecuencias de la subsanación permitida por el acreedor (art. III.- 3:203). Reitera la posibilidad para el acreedor de suspender su propia prestación como único remedio disponible, durante el plazo de la suspensión. Con todo, si a pesar de la subsanación subsisten daños, puede reclamarlos el acreedor. Y otro tanto sucede si producida la subsanación se mantiene la falta de conformidad, caso en el que se abren todos los remedios para el acreedor.

(e) Finalmente, cronológicamente el primer texto trata sobre la coincidencia entre la subsanación y el reemplazo de la prestación no conforme. El reemplazo de la prestación no conforme es considerado en propiedad como un remedio en todos los instrumentos de unificación, pero bien puede ser la medida subsanatoria permitida por el acreedor. Frente a esta situación, el acreedor debe restituir lo reemplazado, y el acreedor no debe pagar por el uso de la cosa reemplazada en el tiempo previo al reemplazo.

\section{ii. CESL}

Otro desarrollo de la subsanación fue efectuado por la CESL en su artículo $109^{60}$. Pero, a diferencia de los PICC, PECL y el DCFR, y al igual de la CISG

\footnotetext{
59 TOMÁs (2012), p. 596.

60 "Subsanación por el vendedor

1. El vendedor que haya realizado una oferta de cumplimiento anticipado y al que se le haya notificado que el cumplimiento no es conforme con el contrato podrá hacer un nuevo ofrecimiento de cumplir con la obligación, en conformidad con los términos que la regulan, si es posible hacerlo antes de que la obligación venza.

2. En los casos no contemplados en el apartado 1, el vendedor que haya realizado una oferta de cumplimiento que no sea conforme con el contrato podrá, sin demora indebida cuando se le notifique la falta de conformidad, ofrecer subsanarla corriendo con los gastos.

3. La notificación de que el contrato ha sido resuelto no excluye el ofrecimiento a subsanar el incumplimiento.

4. El comprador sólo podrá rechazar la oferta de subsanación si:

(a) la subsanación no pueda llevarse a cabo sin demora y sin molestias importantes para el comprador;

(b) el comprador tiene un motivo para desconfiar del cumplimiento futuro del vendedor, o

(c) el retraso en el cumplimiento supondría un incumplimiento esencial.

5. El vendedor tendrá un plazo razonable para llevar a cabo la subsanación.
} 
está pensada para la compraventa, por lo que hay algunas particularidades que conviene destacar.

La primera cuestión que salta a la vista es que la subsanación sólo ha quedado aplicable a las compraventas entre empresarios (business-to-business [B2B] contracts), en conformidad al art. 106(b)(a) CESL, y no es aplicable en materia de compraventa con consumidores (business-to-consumer $[B 2 C]$ contracts). Sólo se acepta la subsanación en los contratos de servicios relacionados con una compraventa de consumo (art. 155[2]), a menos que se trate de una instalación incorrecta regulada en el art. $101^{61}$.

Zoll nos informa que la principal justificación para la exclusión de los contratos de consumo (B2C) está relacionada con el carácter transnacional de los contratos que pretendía regular la CESL. En este contexto, la subsanación arrastraría al consumidor a problemas de distancia, de idioma y de distintas jurisdicciones que sobresofisticaría una relación que debería ser más bien simple. Por lo tanto, en materia de contratos de consumo (B2C) un derecho a la subsanación por el vendedor/proveedor complicaría las soluciones para el comprador, por lo que la resolución contractual podría tener mayor beneficio al consumidor ${ }^{62}$.

Esta solución propuesta por la CESL para los B2C es más evidente que la del DCFR. En efecto, el art. IV.A.- 4:201 DCFR establece un derecho amplio del consumidor para provocar la resolución contractual por cualquier clase de incumplimiento, a menos que la falta de conformidad sea menor. Sin embargo, no se pronuncia, por lo menos expresamente, de la exclusión de la posibilidad de subsanación en los contratos con consumidores como sí lo hizo la CESL. De hecho, el art. IV.A.- 4:201 DCFR sujeta el ejercicio de la resolución por el consumidor a las reglas del libro III, Capítulo 3, Sección 5, que son las generales de resolución (termination en la terminología del DCFR), lo que podría generar

6. El comprador podrá dejar en suspenso su propia prestación mientras se encuentre pendiente la subsanación, pero los derechos del comprador que sean incompatibles con permitir al vendedor un plazo para llevar a cabo la subsanación se suspenderán hasta el vencimiento de dicho plazo.

7. A pesar de la subsanación, el comprador conservará el derecho a exigir la indemnización de los daños por el retraso y por cualquier perjuicio causado o que no pudo ser evitado por la subsanación".

${ }^{61}$ El artículo 101 regula aquellos contratos de compraventa de consumo que suponen la instalación de algunos de sus componentes o de contenidos digitales. En materia de contratos de compraventa entre empresarios (B2B), la técnica de la CESL fue derivar estos contratos a los servicios relacionados regulados en el capítulo 15, arts. 147 y ss. CESL.

${ }^{62}$ Zoll (2012b), p. 497. Esta solución es puesta en duda por MACQueEn y otros (2013), pp. 644-645. Adelantamos, en todo caso, que en el apartado III de este trabajo propondremos un derecho a la corrección del cumplimiento en el derecho chileno de consumo. 
algún eventual problema interpretativo si el Borrador llegase a materializarse como norma sustantiva ${ }^{63}$.

Ahora, el texto de la CESL también tiene otras particularidades frente al DCFR que es necesario destacar.

(a) Al igual que el DCFR se distingue la subsanación anticipatoria de la regular (art. 109[1] CESL), aun cuando no tengan idéntica redacción ${ }^{64}$.

(b) La mecánica de la subsanación es un tanto distinta a la del DCFR. Si bien se distingue entre la proposición por el deudor de la subsanación después de notificada a éste la falta de conformidad, no se restringe por ese hecho la posibilidad de que el acreedor notifique, a su vez, su voluntad en dar por resuelto el contrato. Sólo que a la notificación de la resolución no se le confieren todos sus efectos, sino más bien se le suspende hasta que el acreedor subsane la falta de conformidad, situación en que quedará sin efecto la notificación; o bien, que se mantenga la falta de conformidad, caso en el que la resolución se producirá automáticamente a la extinción del plazo de corrección. Aunque no lo establece expresamente en texto de la CESL, ZoLL es de la opinión que la norma debería ampliarse por vía interpretativa a la reducción del precio, pues tiene un sentido similar al de la resolución ${ }^{65}$.

(c) La CESL no incluyó como causal de rechazo de la subsanación que ésta sea inapropiada a las circunstancias, como sí lo hace el DCFR (parágrafo 5).

(d) La CESL reitera luego que cualquier ejercicio de los derechos del acreedor se suspende hasta que se subsane la prestación no conforme, o bien, hasta que venza el plazo para subsanar, o incluso si la subsanación resulta también no conforme (parágrafo 6). La verdad es que si se incluye la suspensión de la reducción del precio con la suspensión de la facultad resolutoria durante el plazo de subsanación en el parágrafo 3, esta aclaración de la CESL tiene poca utilidad, pues en verdad lo único que podría ya suspenderse es la indemnización de daños ${ }^{66}$.

\footnotetext{
${ }^{63}$ Aun cuando el DCFR no sólo se trata de un Borrador, es dudoso que en algún país pueda el proveedor imponer el clausulado de este Borrador a los contratos de consumo, pues podría violar la normativa interna que regula los contratos de consumo, como asimismo la normativa comunitaria.

${ }^{64}$ Para la subsanación regular, en el art. III.-3:202(2) DCFR se alude a los casos en que el deudor no pueda subsanar en el tiempo estipulado para el cumplimiento; en cambio, en la CESL, art. 109(2) se habla de los casos no cubiertos en el parágrafo 1. Más allá de la diferente redacción, esto apunta a que puede suceder que el deudor solicite antes del término original para el cumplimiento la subsanación, sin embargo, termine cumpliendo en el plazo suplementario. Sobre el particular, véase: MACQueEN y otros (2013), pp. 634-635.

${ }^{65}$ Zoll (2012b), p. 500.

${ }^{66}$ En el mismo sentido, Zoll (2012b), p. 502. Con todo, el mismo autor se pregunta si también se suspende el derecho para provocar la anulabilidad del contrato por vicios del consentimiento.
} 
En el resto el texto de la CESL es concordante con el del DCFR.

\section{Aspectos comparativos de la subsanación en los instrumentos de derecho contractual uniforme y su relación con la restricción de la resolución por incumplimiento}

Luego de una revisión de cómo la subsanación ha sido recogida en los instrumentos de derecho contractual uniforme, conviene hacer algunas precisiones comparativas respecto de todos estos instrumentos.

A pesar de las distintas redacciones y acercamientos a la institución en los distintos instrumentos, hay al menos un cierto espíritu común en el recogimiento de esta figura. Y ello podría indicar que nos encontramos verdaderamente frente a una figura representativa del moderno derecho uniforme de los contratos.

Frente a esta realidad, creemos que es necesario evaluar comparativamente entre estos instrumentos tres materias, a saber: (a) si la subsanación corresponde a un derecho del deudor; (b) si corresponde a un límite a la facultad resolutoria, y (c) la relación entre la subsanación y otras medidas favorables al cumplimiento.

\section{a. La subsanación como medio de promoción al cumplimiento conforme: ¿un verdadero derecho del deudor para cumplir a pesar de la falta de conformidad?}

Para algunas legislaciones resulta un tanto extraño que se le conceda a lo menos nominalmente un derecho ("right") al deudor para subsanar la falta de conformidad, en circunstancias que él mismo no ha podido cumplir en forma con la prestación debida. Así, por ejemplo, en el derecho inglés no estaba contemplada esta posibilidad ${ }^{67}$, a diferencia de lo que sucedía en el derecho norteamericano que sí la reguló en el UCC. Tampoco en el ámbito de la tradición de derecho continental, pues en países como Chile, y los que siguieron nuestro Código debido a la redacción del art. 1489 del Código Civil chileno, no contempla la facultad judicial de moderar la demanda de resolución con modalidades alternativas ${ }^{68}$.

Sin perjuicio de que a esta institución se le denomine como un "derecho" del deudor para corregir su prestación no conforme, cabe determinar cuáles son los límites a los que se enfrenta para ejercer esta prerrogativa.

Así, nos detendremos en dos aspectos que ayudan a entender la extensión de esta facultad: el reconocimiento de la subsanación anticipatoria y los límites generales a la corrección del cumplimiento no conforme.

67 BRIDGe (2013), p. 585.

${ }^{68}$ Contardo (2015), pp. 109 y ss. 


\section{i. El reconocimiento de la subsanación anticipatoria}

En primer lugar, puede observarse que la subsanación anticipatoria es reconocida de manera expresa en la CISG, en los PECL, en el DCFR y en la CESL. Pero ello no sucede en los PICC.

A pesar de que los PICC no la incluyen a lo menos de forma propositiva (como en el DCFR y en la CESL), los instrumentos prefieren que el cumplimiento anticipado no entorpezca la posibilidad de que el deudor logre la conformidad en el tiempo originalmente pactado para el cumplimiento. Esta sería, a nuestro entender, una forma de promoción del cumplimiento conforme, pues evita que el acreedor pueda declarar la falta de conformidad, y ejercer la gama de remedios que tenga disponible.

Aunque la utilidad de la subsanación anticipatoria se ha discutido en el sentido de que lo más probable es que frente a una entrega anticipada no conforme el deudor termine subsanando después del plazo para el cumplimiento y no antes como pretende la institución ${ }^{69}$, nos da la impresión que es útil su reconocimiento por dos razones. En primer lugar, evita que el acreedor declare el incumplimiento definitivo antes del vencimiento del mismo; y en segundo lugar, aunque la práctica indique una cuestión distinta, bien cabe dejar abierta la puerta para una subsanación durante el plazo original para el cumplimiento.

De esta manera, puede concluirse que la corrección anticipatoria se configura como un verdadero derecho del deudor, pues el cumplimiento anticipado: (1) no implica una renuncia del plazo por parte del deudor; (2) y entorpece el derecho del acreedor a solicitar la resolución también anticipatoria (anticipatory breach).

\section{ii. Los límites}

Desde otro punto de vista, puede señalarse que los instrumentos colocan algunas cortapisas para el ejercicio de la subsanación. Éstas son, en resumen, que:

(1) la subsanación pueda producir una demora injustificada en el cumplimiento de la obligación o tornar el incumplimiento en esencial en atención al plazo (arts. 48[1] CISG, 7.1.4[1][d] PICC, III.-3:203[a] DCFR, 109[4][a] y [c] CESL);

(2) la subsanación cause molestia o inconvenientes excesivos para el acreedor (arts. 48[1] CISG, 109[4][a] CESL);

(3) el acreedor tenga desconfianza fundada en que subsanación no pueda completarse (arts. III.- 3:203 [c] DCFR y 109[4] [b] CESL), y

(4) la subsanación no sea apropiada a las circunstancias (arts. 7.1.4[1][b] PICC y III.-3:203[d] DCFR).

\footnotetext{
${ }^{69}$ Con el riesgo de transformar un contrato de entrega única en uno de entregas sucesivas, como apunta BRIDGE (2013), p. 585.
} 
La limitación común a todos los instrumentos (excluidos los PECL, por las razones anotadas anteriormente) está relacionada con la incapacidad del deudor para subsanar dentro de plazo suplementario que se le otorgue al efecto; o bien, si la subsanación es anticipatoria, antes del vencimiento del plazo originalmente pactado con el carácter de esencial. Aquí lo relevante no es que la falta de conformidad detectada por el acreedor sea esencial, sino que el deudor pueda cumplir dentro de plazo.

De ello también se deriva que tanto el DCFR y la CESL aclaren que el acreedor pueda repudiarla si se tiene una desconfianza fundada en que la subsanación no

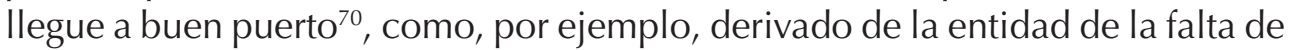
conformidad (cuando sea muy grave para ser subsanada), conducta desleal del vendedor o falta de competencia demostrable del deudor ${ }^{71}$. Es decir, el deudor no estaría en condiciones de subsanar, lo que justifica, asimismo, la causal de "molestia o inconvenientes excesivos", que supone un grado de cooperación importante del acreedor hacia el deudor ${ }^{72}$, en circunstancias que este último debería subsanar por su cuenta y asumiendo los costos.

Analizadas de esta manera las limitaciones, puede concluirse que ellas son menores, pues han sido relegadas a casos más graves de incumplimiento, o a los que pueden derivar en incumplimientos esenciales, aun cuando se ejerza la subsanación. De tal suerte, que en la mayoría de los casos el deudor llano a cumplir puede estar en condiciones de cumplir en el plazo adicional para el cumplimiento, con pocas posibilidades de que el acreedor pueda oponerse a la subsanación. Vistas así las cosas, puede deducirse que aunque no se trata de un derecho absoluto o potestativo del deudor, la segunda oportunidad para satisfacer correctamente el interés del acreedor se otorga de manera más bien amplia, aun cuando en el plazo original ya haya vencido.

\section{b. La subsanación como límite a la facultad resolutoria}

Si se estima que el deudor tiene un derecho a la subsanación, con las escasas limitaciones descritas, entonces cabe evaluar en qué medida se ve atenuada la facultad resolutoria. Se trata sólo de describir el otro lado de la moneda, es decir, en qué medida la facultad resolutoria se restringe por el evento del ejercicio de la subsanación.

En primer lugar, hay una limitación respecto a la posibilidad temporal de cumplir la prestación. Si por el ejercicio de la subsanación el deudor traspasará

\footnotetext{
${ }^{70}$ En Chile, la resolución por pérdida de confianza ha sido estudiada por MejíAs (2011), pp. 264-279.

71 Zoll (2012b), p. 501.

${ }^{72}$ Zoll (2012b), p. 501.
} 
el límite del plazo no esencial, para luego pasar al esencial, el acreedor razonablemente puede oponerse a la rectificación y solicitar la resolución.

El segundo límite está dado por la solicitud del deudor en subsanar la prestación. Si el deudor no manifiesta su voluntad en subsanar, no hay derecho posterior a la subsanación y, por tanto, el acreedor frente a la segunda inactividad del deudor puede solicitar la resolución contractual.

Una tercera limitación está dada por el hecho que el único remedio disponible al acreedor, durante el plazo otorgado para la corrección, es la suspensión del cumplimiento de la prestación propia del acreedor. En la compraventa, el ejemplo más fácil de observar es que si las mercaderías no son conformes y el vendedor quiere subsanar, el comprador puede suspender el pago del precio. Incluso, tal como ya se hizo mención, en el DCFR si el acreedor solicita la resolución dentro del plazo suplementario, esta notificación no surge efectos sino cuando vence dicho término.

Teniendo en consideración lo anterior, puede concluirse que no sólo el ejercicio de la subsanación representa un límite a la resolución, sino incluso que desde el punto de vista de los requisitos de la misma (la resolución), la anuencia del acreedor en la corrección del cumplimiento puede ser considerado en la práctica como un verdadero requisito de la resolución.

\section{c. Relación entre la subsanación y otras medidas favorables al cumplimiento conforme}

En vista del panorama descrito, bien cabe relacionar el derecho a la corrección del cumplimiento con otras instituciones características del derecho uniforme. Nos referimos, en especial, al plazo adicional para el cumplimiento, y los remedios de la reparación y la sustitución.

\section{i. Subsanación y plazo adicional para el cumplimiento}

La subsanación y el plazo adicional para el cumplimiento están en muy estrecha relación.

En el sistema de la CISG se permite el cumplimiento posterior al plazo, cuando la prestación es posible de ser satisfecha través de la institución del plazo adicional para el cumplimiento (aditional time for performance, arts. 43 y 63 CISG).

El sistema de esta institución es el siguiente. Retrasada la obligación, el acreedor puede estar en duda en notificar inmediatamente la resolución ${ }^{73}$, pues puede estimarse que el incumplimiento no ha sido esencial en atención

\footnotetext{
${ }^{73}$ La expresión "notificar" no está tomada en el sentido frecuente que se le da en la tradición chilena -como notificación judicial-, sino en el marco del ejercicio extrajudicial de la resolución en el sistema deViena (tomado del nachfrist alemán), es decir, mediante una comunicación extrajudicial del acreedor
} 
al plazo. Pues bien, para configurar la esencialidad del incumplimiento, el acreedor puede conceder este plazo adicional para el cumplimiento, de tal suerte que, vencido él mismo, se configura el incumplimiento suficiente para demandar la resolución.

De esta manera, producido el incumplimiento no esencial, puede el acreedor otorgar un plazo de gracia para subsanar.

Con todo, tal como hemos revisado, ambas instituciones aunque pueden coincidir, no necesariamente se superponen. Ello se debe a que el right to cure está relacionado con la falta de conformidad en general; y el plazo adicional para el cumplimiento con la esencialidad del plazo para cumplir. Así, si el plazo para el cumplimiento no es esencial y se configura un incumplimiento total, hay lugar al aditional time for performance, sin necesidad de recurrir a la corrección; pero, si la falta de conformidad es no esencial, y tampoco el plazo, pueden coincidir ambas instituciones, cuando la corrección no es anticipatoria.

\section{ii. Subsanación, reparación y sustitución}

Las otras dos instituciones que se encuentran muy relacionadas con la subsanación son la reparación y la sustitución. Aun cuando en los instrumentos de derecho contractual uniforme se distinguen del cumplimiento específico, MORAlEs estima que en aquellas que no están consagradas de manera expresa, deben subsumirse en el cumplimiento en naturaleza ${ }^{74}$.

La relación entre la subsanación y la reparación y sustitución estriba en que la subsanación normalmente las comprende, es decir, es frecuente que el deudor tenga derecho a reparar o sustituir. La diferencia con ellas es que la primera se configura como una prerrogativa del deudor, quien puede forzar al acreedor a la reparación o sustitución, siempre que se cumplan con los requisitos para su procedencia. En cambio, las segundas son consideradas remedios del acreedor. Otra diferencia entre ellas es que la subsanación puede ser anticipatoria, de tal manera que no es necesario para todos los casos (por lo menos en teoría) que se otorgue un plazo adicional para el cumplimiento.

\section{El derecho a la corrección del incumplimiento en el derecho chileno de contratos. Posibilidades exploratorias para su configuración en Chile}

Más allá del reconocimiento de la CISG sobre la posibilidad de corregir el incumplimiento no conforme, no encontramos en nuestra legislación civil, según

al deudor de su intención de no continuar con la relación obligatoria. Sobre el sistema de Viena, en Chile: VIDAL (2006), pp. 93-108.

${ }^{74}$ Morales (2006), pp. 195-199. 
nuestras apreciaciones, referencias expresas a ella en nuestro ordenamiento civil. Con todo, si el derecho chileno de contratos está transitando hacia una relectura interpretativa que reconozca la falta de conformidad, bien cabe explorar algunas bases que permitan la inclusión de esta figura en el derecho de contratos.

De esta manera, creemos que hay bases suficientes para su configuración, tanto en el derecho civil (1) como en el derecho del consumo (2).

\section{En el Código Civil chileno}

El método seguido por nuestro Código Civil en materia de incumplimiento, fundado en la tradición romana, se basa, en general, en un sistema que podría llamarse del "todo o nada". O el deudor cumple la prestación, o no la cumple. Y si no la cumple, podrían ejercerse la totalidad de los remedios, incluida la resolución. Es decir, en apariencia, no cabría el ejercicio de la subsanación por el deudor.

Prueba de esto es el art. 1826 del Código, que regula la hipótesis de incumplimiento del vendedor sólo por falta de entrega, no por entrega disconforme. En virtud de esta norma, o el deudor entrega el cuerpo cierto, o no: no hay espacios para puntos intermedios. Por el contrario, el equivalente a la falta de conformidad es tratada a propósito de los vicios redhibitorios, que más se acerca al error (por ello está sancionado con rescisión) que a un caso de incumplimiento, sin perjuicio de las posibilidades de concurso con el régimen general de incumplimiento ${ }^{75}$.

La razón de este sistema seguido por el Código es bien simple: éste ha sido fundado en las entregas de una especie o cuerpo cierto. La entrega de especie supone que no hay en el mercado forma de suplirla, menos de subsanarla, pues es el propio deudor quien la entrega y depende de él si se subsana, pues sería el único quien podría hacerlo.

Con todo, en el tráfico actual, la entrega incluso de especies o cuerpos ciertos permite subsanación. Hay casos en que la especie es compleja y supone la reunión de variados componentes que permiten sustitución. Y, en otros casos, la subsanación incluso permite otros partícipes del mercado ${ }^{76}$.

En el mercado del género, la cuestión es distinta: hay sustitutos en el mercado, no siempre de la misma calidad, pero permiten, en parte, satisfacer el interés del acreedor. Y ello también permite subsanación, con más facilidad incluso que en las entregas de especies o cuerpos ciertos.

Este sistema del "todo o nada" así configurado, nos da la impresión que no es aceptable dadas las necesidades del tráfico actual. En el tráfico vigente, las

75 Sobre el particular, véase De LA MAZA (2014).

${ }^{76}$ Morales (2006), pp. 199-202. 
partes resuelven normalmente sus problemas extrajudicialmente; y en el caso en el que, dada la lentitud justificable de los medios procesales de justicia, pueden resolverse sus problemas vigentes a través de la indemnización de perjuicios, cuando ya las posibilidades extrajudiciales hayan sido completadas. La necesidad de abaratar los costos de transacción y judiciales, como asimismo de favorecer la rapidez en el tráfico, imponen la necesidad de favorecer una segunda opción para el cumplimiento dentro de ciertos márgenes que toleren el mal menor (el incumplimiento) en aras de favorecer la conformidad contractual.

Frente a este panorama, el punto al que queremos atacar es que al deudor sí debe considerársele la facultad para evitar el ejercicio de algunos remedios, en especial la resolución, ofreciendo un cumplimiento alternativo de la prestación, más la indemnización de perjuicios.

Así, una respuesta exploratoria, nos podría indicar que si el deudor ofrece, o ha ofrecido, subsanar la prestación, de manera razonable, no sería posible exigir, al menos, la resolución del contrato. Si se negara esta facultad, se estaría permitiendo un ejercicio que podría calificarse de abusivo de la facultad resolutoria. ${ }^{77} \mathrm{Y}$, aun sin calificarlo como un ejercicio abusivo, podría llegar a estimarse que la facultad de subsanar es una carga del deudor, quien puede utilizarla para evitar que su incumplimiento sea calificado de esencial. De esta manera, probado que el deudor ha ofrecido subsanar la prestación y el acreedor lo repudia, no podría entonces calificarse el incumplimiento como esencial o resolutorio.

Con todo, debemos reconocer que el sistema judicial de ejercicio de la resolución lleva, como consecuencia inevitable, a impedir caminos alternativos a la resolución ${ }^{78}$ y, por tanto, a la subsanación. Por ello, lo conveniente sería permitir la corrección del cumplimiento en el espacio previo a la judicialización del pleito, y oponerla al tribunal como excepción perentoria.

Ahora bien, debe tenerse presente que la falta de ejercicio de la carga de subsanar favorece también al acreedor. Frente a la posibilidad de que se estime que el incumplimiento no ha sido resolutorio, bien podría el acreedor hacer presente en el juicio resolutorio que el deudor no ha ofrecido subsanar la falta de conformidad, o bien, que la corrección también ha sido disconforme. Esto ayudaría a configurar el incumplimiento necesario para dar lugar a la resolución frente a la renuencia o incapacidad del deudor de subsanar, lo que se configura, asimismo, como un argumento fuerte en favor de la resolución contractual, lo que se complementa con la idea de frustración del interés contractual.

77 Tal como lo ha sugerido López (2012), pp. 45-47.

${ }^{78}$ Sobre el ejercicio de la resolución en el marco del sistema del "todo o nada" en el Código Civil, véase CONTARDO (2015), pp. 111-112. 
Por cierto, la proposición que efectuamos debe circunscribirse bajo la aceptación de la noción de plazo esencial y no esencial que hemos defendido en otro lugar ${ }^{79}$. El marco en el que debe aceptarse la subsanación son los Ilamados plazos "no esenciales", los que deben ser calificados por el juez cuando las partes no hayan efectuado una determinación expresa. De esta manera, la subsanación puede tener lugar cuando el plazo es "no esencial", lo que es perfectamente coincidente con el sistema moratorio del art. 1551 $\mathrm{N}^{\circ}$ s. 1 y $3^{80}$.

En el plano de la subsanación anticipatoria, su incardinación en el derecho chileno nos parece que merece algunas apreciaciones adicionales. Recordemos que nos encontramos en la situación que el deudor cumple antes del vencimiento del plazo (sea éste esencial o no). La doctrina nacional uniforme estima que el deudor puede renunciar al plazo cumpliendo antes la prestación, siempre que el plazo haya sido colocado en su exclusivo beneficio ${ }^{81}$. Pues bien, frente a un cumplimiento anticipado pero no conforme, ¿debe estimarse que el deudor ha renunciado al plazo para todos los efectos, de tal suerte que el acreedor estaría facultado para ejercer desde ya la resolución contractual o los demás remedios que resulten pertinentes?

Nos da la impresión que frente a un cumplimiento anticipado, la renuncia del plazo no debe impedir al deudor la posibilidad de subsanar la prestación, por lo menos, durante el plazo que reste para el cumplimiento de la obligación, pues mientras esté pendiente la falta de conformidad todavía no perjudica al acreedor. Somos conscientes, tal como se hizo presente con anterioridad, que frente a un cumplimiento no conforme anticipado es poco probable que el deudor alcance siempre a cumplir dentro del plazo original. Pues bien, en estos casos, con mayor razón debe evaluarse la (no) esencialidad del plazo y ponderar los intereses de las partes en aras de permitir la subsanación. Ahora, desde el punto de vista del acreedor, también es un argumento fuerte -más fuerte aún- en favor de la resolución el hecho que el deudor, pudiendo subsanar en el plazo todavía restante, no lo haya hecho.

\section{En el derecho de la protección del consumidor}

Tampoco en el derecho chileno de protección al consumidor hay referencias expresas a una subsanación por el deudor, que corresponde al proveedor (art. $1^{\circ} \mathrm{N}^{\circ} 2$ de la ley $\mathrm{N}^{\circ} 19.496$, en adelante, LPDC).

\footnotetext{
${ }^{79}$ Contardo (2014b), pp. 97-100.

${ }^{80}$ Contardo (2014b), p. 99.

${ }^{81}$ Por todos, PeÑailillo (2003), pp. 484-485.
} 
En el derecho de la protección del consumidor hay algunas particularidades que conviene estudiar con detención, pues la ley $N^{0} 19.496$ regula distintos supuestos de falta de conformidad. Recordemos, antes de analizar los distintos supuestos de la LPDC, que en el marco de la CESL se decidió no otorgar el derecho a la subsanación en materia de B2C, pero por problemas transfronterizos y no dogmáticos en la configuración del sistema de protección del consumidor ${ }^{82}$. Hacemos presente lo anterior, puesto que en parte de la doctrina nacional se ha instalado la opinión que el ejercicio de los remedios a favor del consumidor, y que son irrenunciables de éste (art. $4^{\circ}$ LPDC), son de libre elección de la parte acreedora (el consumidor), de tal suerte que el proveedor no podría, en principio, limitar su ejercicio, lo que impediría de alguna manera el ejercicio de la subsanación. Con todo, teniendo en vista las consideraciones expuestas sobre la necesidad de adoptar un sistema de conformidad, y favorable a éste, bien cabe revisar los distintos escenarios que coloca la LPDC.

Vamos a los distintos supuestos.

El primero es el de los defectos de cantidad o anomalías cuantitativas ${ }^{83}$, reguladas en el art. 19 LPDC. La norma establece que frente a ellas, el consumidor tiene derecho a la "reposición" (sustitución) del producto, o "en su defecto" la "bonificación de su valor en la compra de otro" o la "devolución del precio que haya pagado en exceso".

La expresión "en su defecto" ha Ilevado a CORRAL a pensar que hay una jerarquía de los remedios que ofrece la norma, de tal suerte que debería subsanarse el incumplimiento primariamente a través de la sustitución antes del ejercicio de los demás remedios ${ }^{84}$. Esta opinión no es compartida por

\footnotetext{
${ }^{82}$ Cabe hacer presente que la Directiva 1999/44/CE permite la subsanación en su artículo 3.3: "En primer lugar, el consumidor podrá exigir al vendedor que repare el bien o que lo sustituya, en ambos casos sin cargo alguno, salvo que ello resulte imposible o desproporcionado.

Se considerará desproporcionada toda forma de saneamiento que imponga al vendedor costes que, en comparación con la otra forma de saneamiento, no sean razonables, teniendo en cuenta:

- el valor que tendría el bien si no hubiera falta de conformidad,

- la relevancia de la falta de conformidad, y

- si la forma de saneamiento alternativa pudiese realizarse sin inconvenientes mayores para el consumidor.

Toda reparación o sustitución deberá llevarse a cabo en un plazo razonable y sin mayores inconvenientes para el consumidor, habida cuenta de la naturaleza de los bienes y de la finalidad que tuvieran los bienes para el consumidor".

Sin hacer alusión a un derecho del deudor para subsanar (right to cure), lo cierto es que la Directiva, al conceder una preferencia hacia la reparación y sustitución, de alguna manera favorece la subsanación, aunque tal como se hizo presente con anterioridad estas instituciones no son idénticas, pero sí están relacionadas.

${ }^{83}$ BarRientos (2013a), pp. 518-523.

${ }^{84}$ Corral (2006), pp. 98-99.
} 
BARRIENTOS, quien sostiene que esta interpretación no es sostenible, pues no favorece al consumidor ${ }^{85}$.

Las demás disconformidades en las ventas de consumo se regulan en las letras a), b) c), d), f) y g) art. 20 LPDC, que son bien similares a las del art. 35 $\mathrm{CISG}^{86}$.

El encabezado de la norma sugiere que el consumidor tendría libertad para exigir cualquiera de los remedios que la ley establece, a saber, la reparación, la reposición, la devolución del precio (resolución) y la indemnización de perjuicios ${ }^{87}$, lo que se vería corroborado por el art. $21 \mathrm{LPDC}^{88}$. Sin perjuicio de lo anterior, queremos colocar nuestra mirada en la letra e). La falta de conformidad descrita en esta letra contiene dos supuestos, uno de los cuales nos interesa analizar. El primero de ellos se produce cuando luego de prestado el servicio técnico, subsisten las deficiencias de la cosa a las que se refiere la letra c) del mismo artículo. El segundo supuesto consiste en que a pesar de la reparación, aflora una disconformidad distinta (oculta aparentemente). Nos interesa sólo la primera.

La norma no establece que la reparación sea jerárquicamente superior al resto de los remedios, como podría desprenderse del art. 19 (si se sigue la opinión de CORRAL). Sin embargo, se coloca en el caso que el proveedor intentó subsanar a través de la reparación y no lo hizo de manera correcta. Frente a esta posibilidad, se abren los demás remedios. Aquí nosotros observamos a lo menos un germen de la subsanación.

Otro tanto sucede con el inciso final del art. 20. La norma aclara que en la reposición (sustitución) de un producto que está conformado por partes o piezas, es suficiente la reposición de la parte o pieza defectuosa, con lo que se soluciona con ello la falta de conformidad. Esta es otra manifestación que nosotros observamos de una posible subsanación.

En materia de desperfecto en los servicios (o servicios no conformes), en virtud del art. 41 [2] LPDC que establece los remedios a favor del consumidor ${ }^{89}$, también podría pensarse que establece una suerte de primacía entre los remedios. Así, la LPDC confiere el derecho del consumidor de optar por la prestación del servicio sin costo, y de nuevo "en su defecto" la devolución del precio pagado y la indemnización de perjuicios. La norma que también podría interpretarse

\footnotetext{
85 Barrientos (2013a), pp. 520-521.

86 Barrientos (2013b), p. 532.

87 Barrientos (2013b), p. 532.

88 NASSER (2013), pp. 548-549.

89 Contardo (2013), pp. 876 y ss.
} 
en el sentido que le dio CORRAL al art. 19, podría preferir la subsanación a los demás remedios, opinión que en su oportunidad rechazamos ${ }^{90}$.

A partir del examen de las normas antes descritas, bien cabe cuestionarse si la libertad de ejercicio de los remedios podría tener como límite un derecho de subsanación por el proveedor. Además de lo contractual, la cuestión tiene importancia en el ámbito infraccional, pues tal como es ampliamente sabido, los incumplimientos contractuales aparejan infracciones administrativas/ penales a partir del art. 23 LPDC $^{91}$. El punto es que al proveedor no sólo le puede interesar evitar o limitar el ejercicio de los remedios, sino incluso la sanción infraccional.

Un ejemplo de lo que se viene discutiendo puede encontrarse en FranZaNI con Sociedad Comercial Giuseppe y Compañía Limitada ${ }^{92}$. En este caso, la demandante solicitó la devolución del precio (\$9.990 pesos de la época) respecto de unos zapatos comprados que habían presentado fallas. Concurrió solicitando la devolución del precio o la sustitución, pero el proveedor le informó que no se devolvía el dinero y que se repararía el calzado no conforme. Luego de entregar el producto reparado solicitó nuevamente la devolución del precio, lo que nuevamente no accedió el proveedor, puesto que ya se había efectuado la reparación, y el producto se encontraba reparado en poder del consumidor. La Corte de Apelaciones de Talca resolvió que la triple opción del artículo 20 es privativa del consumidor y el proveedor no puede imponer al consumidor uno de los derechos, cual es la reparación.

En este caso, se condenó al proveedor por no permitir el ejercicio del derecho que le interesaba al consumidor. Sin embargo, existió un interés del proveedor en subsanar, y efectivamente se produjo la subsanación, dado que el calzado reparado se encontraba en poder del consumidor.

Nos da impresión que la clave para analizar una posible subsanación en el derecho del consumo está en el ejercicio racional de los remedios de conformidad a la buena fe objetiva. Si el plazo no es esencial y hay posibilidades razonables de subsanación (como se observa en el art. 20 inciso final LPDC) parece razonable que al proveedor se le otorgue la posibilidad de subsanar, de tal manera que pueda corregir la prestación defectuosa y con ello favorecer la conformidad contractual, evitando asimismo una condena infraccional ex art. 23 LPDC. A este respecto, los criterios establecidos en el inciso final del art. 3.3 de la Directiva № 1.999/44/CC sobre determinados aspectos de la venta

90 Contardo (2013), p. 876.

91 Sobre el particular, revísese Barrientos y Contardo (2013), pp. 556-558.

92 Corte de Apelaciones de Talca, rol Nº 66246-2004, 2 de enero de 2008. 
y las garantías de los bienes de consumo a propósito de la reparación y sustitución pueden ser aplicables: "Toda reparación o sustitución deberá llevarse a cabo en un plazo razonable y sin mayores inconvenientes para el consumidor, habida cuenta de la naturaleza de los bienes y de la finalidad que tuvieran los bienes para el consumidor", lo que guarda similitud con las restricciones a la subsanación reconocida por los instrumentos de derecho contractual uniforme.

\section{Conclusiones}

De la presente investigación podemos extraer las siguientes conclusiones:

$1^{\text {a }}$. El derecho a la subsanación del cumplimiento no conforme (right to cure) es una figura reconocida en los instrumentos de derecho contractual uniforme que importa otorgar una segunda oportunidad para el cumplimiento conforme, aun cuando el deudor no haya cumplido en forma e, incluso, le permite cumplir más allá del plazo original destinado para el cumplimiento.

$2^{a}$. El derecho a la subsanación tiene lógica en un sistema unitario de incumplimiento basado en el régimen de conformidad, que supone su favorecimiento. En otras palabras, es de suyo en un régimen de conformidad que se le otorgue al deudor la posibilidad de subsanar el incumplimiento.

$3^{\text {a }}$. El derecho a la subsanación del cumplimiento no conforme representa un límite al ejercicio de los remedios del deudor, en especial, a la facultad resolutoria en la medida que se cumpla con los requisitos suficientes para subsanar.

$4^{a}$. Los límites reconocidos a la subsanación son que ésta pueda producir una demora injustificada en el cumplimiento de la obligación o tornar el incumplimiento en esencial en atención al plazo, que la subsanación cause molestia o inconvenientes excesivos para el acreedor, que el acreedor tenga desconfianza fundada en que la subsanación no pueda completarse y que la subsanación no sea apropiada a las circunstancias.

$5^{\mathrm{a}}$. En el derecho nacional esta figura tiene reconocimiento sólo en la CISG, existiendo un vacío sobre la materia en el derecho chileno de contratos, tanto en el Código Civil como en la LPDC. Sin embargo, se observan bases suficientes que permitan la inclusión de la figura en los órdenes normativos antes enunciados.

\section{BiBLIOGRAFÍA CITADA}

Barendrecht, Mauritz, (2007): "Preface to this volume" en BarendreCht, Mauritz, Jansen, Chris, Loos, Marco, Pinna, Andrea, Cascão, Rui y Van Gulijk, Stéphanie, Principles of European Law. Service Contracts (PEL SC) (Oxford, Oxford University Press), pp. xv-xvi.

Barendrecht, Mauritz, Jansen, Chris, Loos, Marco, Pinna, Andrea, Cascão, Rui y Van GulJjk, Stéphanie (2007): Principles of European Law. Service Contracts (PEL SC) (Oxford, Oxford University Press). 
Barrientos Camus, Francisca (2013a): "Artículo 19", en De la Maza Gazmuri, íñigo y Pizarro Wilson, Carlos (edits.) La protección de los derechos de los consumidores (Santiago, Thomson Reuters), pp. 518-523.

Barrientos Camus, Francisca (2013b): "Artículo 20", en De la Maza Gazmuri, íñigo y Pizarro Wilson, Carlos (edits.) La protección de los derechos de los consumidores (Santiago, Thomson Reuters), pp. 524-538.

Barrientos Camus, Francisca y Contardo González, Juan Ignacio (2013): "Artículo 23", en De la Maza Gazmuri, Íñigo y Pizarro Wilson, Carlos (edits.), La protección de los derechos de los consumidores (Santiago, Thomson Reuters), pp. 556-582.

BJÖRKLUnd, Andrea (2011): "Article 25", en KrÖlL, Stefan, Mistelis, Loukas y Perales Viscasillas, Pilar, UN Convention on Contracts for the International Sale of goods (CISG). Commentary (München, C.H. Bech-Hart-Nomos) pp. 333-351.

BRIDGE, Michael (2013): The international sale of goods (Oxford, Oxford University Press).

Comisión Europea [CE] (2011): "Propuesta de Reglamento del Parlamento Europeo y del Consejo relativo a una normativa común de compraventa europea", COM(2011) 635 final. Disponible en: http://eurlex.europa.eu/LexUriServ/ LexUriServ.do?uri=COM:2011:0635:FIN:ES:PDF [visitado el 25/10/2015].

Contardo González, Juan Ignacio (2013): "Artículo 41", en De la Maza Gazmurı, íñigo y Pizarro Wilson, Carlos (edits.), La protección de los derechos de los consumidores (Santiago, Thomson Reuters), pp. 866-888.

Contardo González, Juan Ignacio (2014a): "Por un sistema de medidas anticipatorias frente al incumplimiento contractual", en Turner Saelzer, Susan y Varas Braun, Juan Andrés (coords.), Estudios de Derecho Civil IX (Santiago, Thomson Reuters), pp. 551-554.

ContaRdo GonzÁlez, Juan Ignacio (2014b): “Una interpretación restrictiva sobre los efectos de la constitución en mora según el 'Código Civil'", en Revista de Derecho de la Pontificia Universidad Católica de Valparaíso (v. XLIII, $2^{\circ}$ semestre), pp. 77-116.

Contardo González, Juan Ignacio (2015): Indemnización y resolución por incumplimiento (Santiago, Thomson Reuters).

CoRral TalCIANI, Hernán (2006): "La responsabilidad por incumplimiento y por productos peligrosos en la ley de protección de los derechos de los consumidores", en Baraona González, Jorge y Lagos Villarreal, Osvaldo (edits.), La protección de los consumidores en Chile. Aspectos sustantivos y procesales luego de la reforma contenida en la ley No 19.955 de 2004 (Santiago, Universidad de los Andes). 
De la Maza Gazmurı, Íñigo (2014): "La tutela del comprador frente a la ausencia de calidades presupuestas en la cosa", en Revista de Derecho de la Pontificia Universidad Católica de Valparaíso (v. XLIII, 2º semestre), pp. 117-159.

De la Maza Gazmurı, Íñigo (2015): "La conformidad de la cosa vendida: adecuación material", en Revista de Derecho (Universidad Austral de Chile) (v. XXVIII, No 1), pp. 79-100.

Díez-Picazo, Luis, Roca, Encarna y Morales, Antonio Manuel (2002): Los principios del derecho europeo de contratos (Madrid, Civitas).

Dimatteo, Larry, Dhooge, Lucien, Greene, Stephanie, Maurer, Virginia y Pagnattaro, Marisa Anne (2005): International Sales Law. A critical Analysis of CISG Jurisprudence (Cambridge, Cambridge University Press).

HonNOLD, John (1999): Uniform Law for International Sales under the 1980 United Nations Convention (The Hague, Kluwer Law International).

Huber, Peter (2011a): "Article 48", en Kröll, Stefan, Mistelis, Loukas y Perales VISCASILLAS, Pilar, UN Convention on Contracts for the International Sale of goods (CISG). Commentary (München, C.H. Bech-Hart-Nomos) pp. 702-710.

Huber, Peter (2011b): "Article 49", en Kröll, Stefan, Mistelis, Loukas y Perales VISCASILlas, Pilar, UN Convention on Contracts for the International Sale of goods (CISG). Commentary (München, C.H. Bech-Hart-Nomos) pp. 711-721.

KrÖll, Stefan (2011a): "Article 35", en KrÖll, Stefan, Mistelis, Loukas y Perales VISCASILlas, Pilar, UN Convention on Contracts for the International Sale of goods (CISG). Commentary (München, C.H. Bech-Hart-Nomos) pp. 487-542.

KrÖll, Stefan (2011b): "Article 37", en Kröll, Stefan, Mistelis, Loukas y Perales VISCASILLAS, Pilar, UN Convention on Contracts for the International Sale of goods (CISG). Commentary (München, C.H. Bech-Hart-Nomos), pp. 550-556.

KrÖLL, Stefan (2011c): "Article 39", en KrÖLl, Stefan, Mistelis, Loukas y Perales VISCASILLAS, Pilar, UN Convention on Contracts for the International Sale of goods (CISG). Commentary (München, C.H. Bech-Hart-Nomos), pp. 594-626.

KeE, Christopher (2004): "Commentary on the Manner in which the Unidroit Principles May Be Used to Interpret or Supplement Article 48 of the CISG". Disponible en: http://www.cisg.law.pace.edu/cisg/principles/uni48.html [visitado el 25/10/2015].

Kruisinga, Sonja (2011): "The Seller's Right to Cure in the CISG and the Common European Sales Law", en European Review of Private Law (vol. 6), pp. 907-919. 
Lando, Ole (1987): "Article 34", en AA.VV., Bianca-Bonell Commentary on the International Sales Law (Milan, Giuffrè), pp. 265-267.

Lando, Ole y Beale, Hugh (edits.) (2000): Principles of European Contract Law. Parts I and II (The Hague, Kluwer Law International).

LIU, Chengwei (2005): "Cure by Non-Conforming Party: Perspectives from the CISG, UNIDROIT Principles, PECL and Case Law". Disponible en: http:// cisgw3.law.pace.edu/cisg/biblio/chengwei1.html [visitado el 25/10/2015].

López Díaz, Patricia Verónica (2012): “El abuso del derecho de opción del acreedor y su importancia en la construcción de un sistema equilibrado de remedios por incumplimiento contractual", en Revista Chilena de Derecho Privado (No 19), pp. 13-62.

MaK, Vanessa (2009): Performance-Oriented Remedies in European Sale of Goods Law (Oxford, Hart Publishing).

Mejías Alonso, Claudia (2011): El incumplimiento resolutorio en el Código Civil (Santiago, Abeledo Perrot-LegalPublishing).

MacQueen, Héctor, Dauner-Lieb, Barbara y Tettinger, Peter (2013): "Specific Performance and Right to Cure", en Dannermann, Gerhard y Vogenauer, Stefan, The common european law in context (Oxford, Oxford University Press), pp. 612-646.

Morales Moreno, Antonio Manuel (2006): "El derecho a la reparación o sustitución de la cosa no conforme y la naturaleza de la obligación del vendedor", en Morales Moreno, Antonio Manuel, La modernización del derecho de obligaciones (Madrid, Civitas).

Müllen-Chen, Markus (2010): "Article 48", en Schwenzer, Ingeborg (edit.), Commentary on the UN Convention on the international sale of goods (CISG) (Oxford, Oxford University Press), pp. 733-745.

Nasser Olea, Marcelo (2013): "Artículo 21", en De la Maza Gazmuri, Íñigo y Pizarro Wilson, Carlos (edits.), La protección de los derechos de los consumidores (Santiago, Thomson Reuters), pp. 539-552.

Peñallillo Arévalo, Daniel (2003): Las obligaciones (Santiago, Editorial Jurídica de Chile).

Plitz, Burhard (2011): "Article 34", en Kröll, Stefan, Mistelis, Loukas y Perales VISCASILlas, Pilar, UN Convention on Contracts for the International Sale of goods (CISG). Commentary (München, C.H. Bech-Hart-Nomos), pp. 473-483.

SAIDOV, Djakhongir (2015): Conformity of goods and documents. The Vienna Sales Convention (Oxford, Hart Publishing). 
SchelHaAs, Harriet (2009): "Article 7.1.1", en Vogenauer, Stefan y Kleinheisterkamp, Jan (edits.), Commentary on the Unidroit principles of international commercial contracts (PICC) (New York, Oxford University Press), pp. 732-734.

SchelHaAs, Harriet (2009): "Article 7.1.4", en Vogenauer, Stefan y Kleinheisterkamp, Jan (edits.), Commentary on the Unidroit principles of international commercial contracts (PICC) (New York, Oxford University Press), pp. 747-752.

Schmitt, Michael (1982): "The Seller's Right to Cure Non-Conforming Tenders-It at First You Don't Succeed, Try to Try Again", en Commercial Law Journal, v. 87 , pp. $283-288$.

SCHNEIDER, Eric (1989): "The seller's right to cure under the Uniform Commercial Code and the United Nations Convention on contracts for the international sale of goods", en Arizona Journal of International and Comparative Law, v. 69, pp. 69-103.

TOMÁs MARTínez, Gema (2012): "La tendencia europea a favorecer la conformidad contractual en el tiempo señalado para el cumplimiento (Right to cure). Especial atención al Borrador del Marco Común de Referencia", en Bosch Capdevila (dir.), Nuevas perspectivas del derecho contractual (Barcelona, Bosch).

UnIDROIT (2010): Unidroit Principles of international commercial contracts 2010 (Roma, Unidroit).

VAQUer Alor, Antoni (2011): "El principio de conformidad: ¿supraconcepto en el Derecho de obligaciones?", en Anuario de Derecho Civil, v. 64, № 1, pp. 5-40.

Vidal Olivares, Álvaro (2006): La protección del comprador. Régimen de la Convención de Viena y su contraste con el Código Civil (Valparaíso, Ediciones Universitarias de Valparaíso).

Vidal Olivares, Álvaro (2007): "Cumplimiento e incumplimiento contractual en el Código Civil. Una perspectiva más realista", en Revista Chilena de Derecho (v. 34, No 1), pp. 41-59.

Vidal Olivares, Álvaro (2009): "La noción de incumplimiento esencial en el 'Código Civil'", en: Revista de Derecho de la Pontificia Universidad Católica de Valparaíso v. XXXII (1 ${ }^{\text {er }}$ semestre), pp. 221-258.

Von Bar, Christian, Beale, Hugh, Clive, Eric y Schulte-Nölke, Hans (2009): "General", en Study Group on a European Civil Code and the Research Group on EC Private Law (Acquis Group), Principles, Definitions, and Model Rules of European Private Law. Draft Common Frame of Reference (DCFR). Outline Edition (Munich. Sellier).

WidMer, Corinne (2010): "Article 34", en Schwenzer, Ingeborg (edit.), Commentary on the UN Convention on the international sale of goods (CISG) (Oxford, Oxford University Press), pp. 560-567. 
ZamiR, Eyal (1991): "Toward a General Concept of Conformity in the Performance of Contracts", en Louisiana Law Review, v. 52, pp. 1-90.

Zoll, Fryderyk (2012a): "Article 99", en Schulze, Reiner (ed.), Commen European Sales Law (CESL). Commentary (Baden-Baden, C.H. Bech-Hart-Nomos), pp. 463-470.

Zoll, Fryderyk (2012b): "Article 109", en Schulze, Reiner (ed.), Commen European Sales Law (CESL). Commentary (Baden-Baden, C.H. Bech-HartNomos), pp. 495-503. 